\title{
Optimal Design of Steel-Concrete Composite I-girder Bridges Using Three Meta-Heuristic Algorithms
}

\author{
Ali Kaveh ${ }^{1 *}$, Mohammad Mahdi Motesadi Zarandi ${ }^{1}$ \\ ${ }^{1}$ Department of Civil Engineering, Iran University of Science and Technology, Narmak, Postal Code 1684613114, Tehran, Iran \\ * Corresponding author, e-mail: alikaveh@iust.ac.ir
}

Received: 29 June 2018, Accepted: 08 October 2018, Published online: 04 December 2018

\begin{abstract}
Bridges are among very important structures in engineering, due to their rather high cost, and this is why optimization of these structures is a challenging problem. In this paper, optimal design of steel-concrete composite l-girder bridges is performed. Three recently developed meta-heuristic algorithms consisting of Colliding Bodies Optimization (CBO), Enhanced Colliding Bodies Optimization (ECBO) and Vibration Particle System (VPS) are utilized for the first time in the optimal design of steel-concrete I-girder bridges. Both continuous and discrete variables are utilized in the process of optimization. Performance and the convergence histories of these algorithms are compared. In order to have a suitable comparison between these algorithms with previous algorithms, PSO is used and results are displayed. This paper focuses on cost optimization the bridges. Furthermore constraints include all of requirements of the code of practice for design. The comparative study has shown that VPS algorithm has better performance than CBO and ECBO. However, all three algorithms act in a way that the final optimized design does not need the addition of the longitudinal stiffener.
\end{abstract}

\section{Keywords}

optimization, meta-heuristics, steel-concrete composite bridge, l-girders

\section{Introduction}

This paper presents, optimal design of a steel-concrete composite I-girder bridge using three newly developed meta-heuristic algorithms, colliding bodies optimization (CBO) [1], enhance colliding bodies optimization (ECBO) [2] and vibrating partial systems (VPS) [3]. Since bridges are among very important structures in engineering and their cost is rather high, the optimization of these structures is an important issue.

In this paper the optimization of steel-concrete composite I-girder bridges is also performed. The span of this bridge exceeds $6 \mathrm{~m}$ and it is a part of a highway and can be placed on or under highway [4]. Composite bridges are lighter, and easier to construct compared to concrete bridges [5]. In these bridges, steel girders are placed under a concrete slab and in order to make sure that steel and concrete act together under the applied loading and deflection, some studs are utilized. These studs are welded from one edge on the upper flange of the girder and other edges are fixed in the concrete slab. A steel-concrete structure combines the performance of steel and concrete and this is done by means of shear connectors. Thevendran et al. [6] has presented the advantages of the composite structures as:
1. Saving in weight of the steel between $30 \%$ and $50 \%$;

2. On a static ultimate load basis, an increase in the overload capacity compared to the non-composite beam;

3. For a given load, a reduction in construction depth with consequent reduction in embankment costs for bridges or storey height in buildings.

In a composite floor system, the steel section is used primarily to resist tension and shear, while the concrete slab acts as a compression element [7]. Multi-action between steel and concrete is very important to increase the moment resistance. If the composite floor is placed on steel girder, it will have no connector to resist against longitudinal shear force, and the concrete floor cannot carry bending moment. Yang and Su [8] studied the effect of fatigue on the composite bridges. Kim et al. [9] investigated the flexural behavior and corresponding load rating of the simply-supported steel I-girder bridges subjected to military truck loads. Barth and $\mathrm{Wu}$ [10] worked on field testing and analytical studies to predict natural frequencies of steel stringer bridges. Razaqpur et al. [11] have studied the effects of concrete nonlinearity and cracking 
and steel yielding on live load distribution in composite concrete slab steel beam bridges. Jagtap and Shahezad [12] presented a comparative study of the pre-stressed concrete girder and steel plate girder for roadway over bridge.

Due to the limitations on material and high cost, structural optimization is important. This is why researchers have developed some methods for reducing the cost of the structures while maintaining strength and durability. Therefore, a topic as optimization evolved with its main purpose being the reduction of the costs and saving the safety requirements of the structures. Long et al. [13] developed a non-linear programming method based on optimization of cable-stayed bridges with composite superstructures and proposed a cost objective function which contained the costs of concrete, structural steel, reinforcements, cables and formwork. Kaveh and Massoudi [14] presented an ant colony system model for cost optimization of composite floor systems based on the load and resistance factor design (LRFD) specification of the AISC. Kaveh [15] performed the optimization of the composite floor systems by using the enhanced colliding bodies optimization (ECBO). Poitras et al. [16] utilized the particle swarm optimization (PSO) for design of composite and non-composite steel floor systems. Hendawi and Frangopol [17] studied on a practical and efficient reliability-based optimization approach for the design of both unstiffened and stiffened composite hybrid plate girders for highway bridges. Luo et al. [18] presented a reliability-based optimization design method of adhesive bonded steel-concrete composite beams with both probabilistic and non-probabilistic uncertainties. Kaveh et al. [19] optimized the cost of bridge superstructures by using a modified version of $\mathrm{CBO}$, denoted by $\mathrm{MCBO}$ and compared the PSO, CBO and MCBO. Pedro et al. [20] presented an efficient two-stage optimization approach for design of the steel-concrete composite I-girder bridges. Senouci and Al-Ansari [21] studied on a genetic algorithm model for the cost optimization of composite beams based on the load and resistance factor design (LRFD) specifications of the AISC. Khatri et al. [22] studied on comparison of the cost of different bridge designs using conventional mild steel Fe 410, high tensile steel Fe 590 and a combination of the two grades of steel. Kravanja et al. [23] presented a comparative study on optimal design of composite steel and concrete floor structures based on the performed multi-parametric mixed-integer non-linear programming (MINLP) approach, and Eurocode specifications. De Munck et al. [24] demonstrated how the need for minimization of both cost and mass can be tackled by a multi-objective optimization. García-Segura and Yepes [25] presented a multi-objective optimization of post-tensioned concrete road bridges in terms of cost, $\mathrm{CO}_{2}$ emissions, and overall safety factor. Hasan et al. [26] summarized numerous researches on straight steel and steelconcrete composite plate girders with emphasis on experimental, theoretical, and numerical work. Linzell, et al. [27] studied the historical perspective on horizontally curved I-girder bridge design in the United States.

Su et al. [28] optimized the deck construction staging for multiple-span continuous steel girder bridges. In their study, the cracking of a typical multiple-span continuous bridge was investigated, and the construction staging was evaluated, and an optimized practice for deck construction staging was provided.

Optimization methods can be categorized into two general types: gradient-based and meta-heuristic approaches. Gradient-based methods consider a starting point, optimize the problem, present exact solutions, and converge quickly, however, in these methods the starting point is very important having high impact on the final solutions.

The word heuristic has its origin in the old Greek word, "heuriskein", which means the art of discovering new strategies or rules for solving problems and the suffix meta, also a Greek prefix, has come to mean a higher level of abstraction in the English language and the term meta-heuristic was introduced by Glover and Kochenberger [29]. Meta-heuristic methods do not need the gradient- information and good start point, while resulting in solutions that have acceptable accuracy. For complex structures, meta-heuristic methods are preferred to gradient-based methods. However, the results obtained from meta-heuristic methods are not necessarily the best ones.

Ant Colony Optimization (ACO) [30], Particle Swarm Optimization (PSO) [31], Harmony Search (HS) [32], Genetic Algorithms (GA) [33], Grey Wolf Optimizer (GWO) [34], Charged System Search (CSS) algorithm [35], and Magnetic Charged System Search (MCSS) [36] are some of the meta-heuristic algorithms for optimization problems. Meta-heuristic algorithms are often inspired by natural phenomena.

After this introduction, Section 2 presents the model for loading. Section 3 introduces optimization. Section 4 introduces penalty function. Sections 5, 6 and 7 briefly introduce the utilized algorithms, and Section 8 provides the results. 


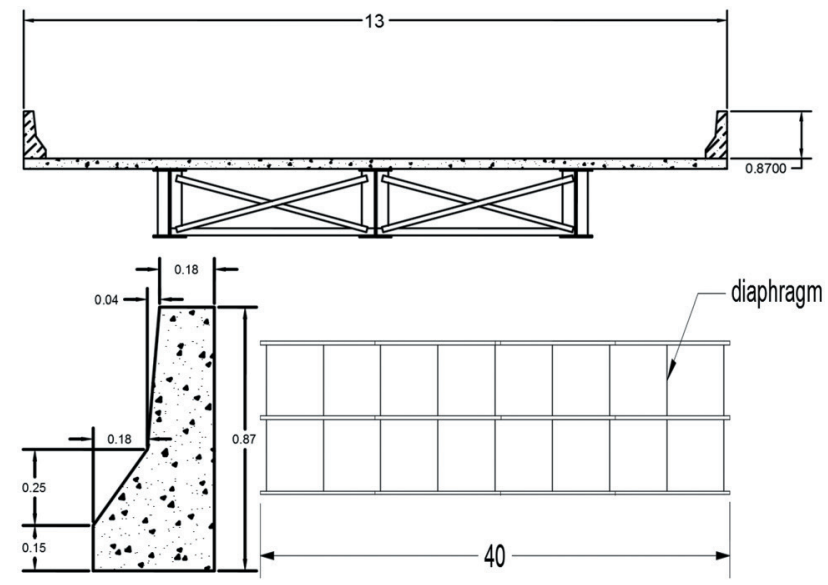

Fig. 1 Geometry of the bridge

\section{Bridge geometry and loading}

In this study optimal design of steel-concrete composite I-girder bridges is conducted. The deck of this bridge possesses reinforced concrete slabs with sufficient shear studs welded on the upper flange. Free spans are considered as $30 \mathrm{~m}, 40 \mathrm{~m}$, and $50 \mathrm{~m}$, having the width of $13 \mathrm{~m}$. Guardroad is $0.87 \mathrm{~m}$ in height. There are transverse diaphragms between girders. The distance and geometry of this bridge are illustrated in Fig. 1.

Dead load on the considered composite bridge is divided into two groups. Dead load group 1 affects non-composite section and it is applied before concrete treatment. Dead load group 2 affects composite section and is applied after concrete treatment. Dead load group 2 includes pavement weight, guard-road, and asphalt thickness. This paper considers the weight of guard-road and $0.125 \mathrm{~m}$ thickness of the asphalt coating.

Dead load group 1 = weight of the girders + weight of the concrete slab.

Dead load group 2 = weight of the guard-road + weight of the asphalt coating.

After specifying the dead loads, bending moments and shear forces can be calculated. In order to find the effect of live load on the bridge, influence line method is used. Using this method, the worst state pf traffic loading can be identified. Effective factors on determination of live load include the number of axles, weight of axles, and distance between axles. Here, live loading model NBR7188 is used [37]. The weight of the track is $450 \mathrm{kN}$ that has three axles with $1.5 \mathrm{~m}$ distances. The weight of each axle is $150 \mathrm{kN}$, and the weight of each tire is $75 \mathrm{kN}$. The distance between the tires is $2 \mathrm{~m}$. A uniform load of $5 \mathrm{kN} / \mathrm{m}^{2}$ also affects the bridge. Figs. 2 to 4 illustrate the considered loading. The impact factor is calculated as: $\varphi=1.4-0.007 \times L$.

In order to calculate the effective force on the internal and external girders according to AASHTO requirement and static rules, concrete slab sets on girders are considered as simply supported, and then the quantity of the support reaction is calculated. This reaction in the supports is equally applied on the girder. For design, first a section is considered and then stresses on concrete and steel are examined. These stresses must not exceed the permitted limit. This study uses AASHTO code [4] and the allowable stress method.

\section{Optimization}

Meta-heuristic algorithms are generally iterative approaches. These algorithms find the final result by applying changes in the design variables and this process is repeated until the best result is obtained. MATLAB software is used for programming.
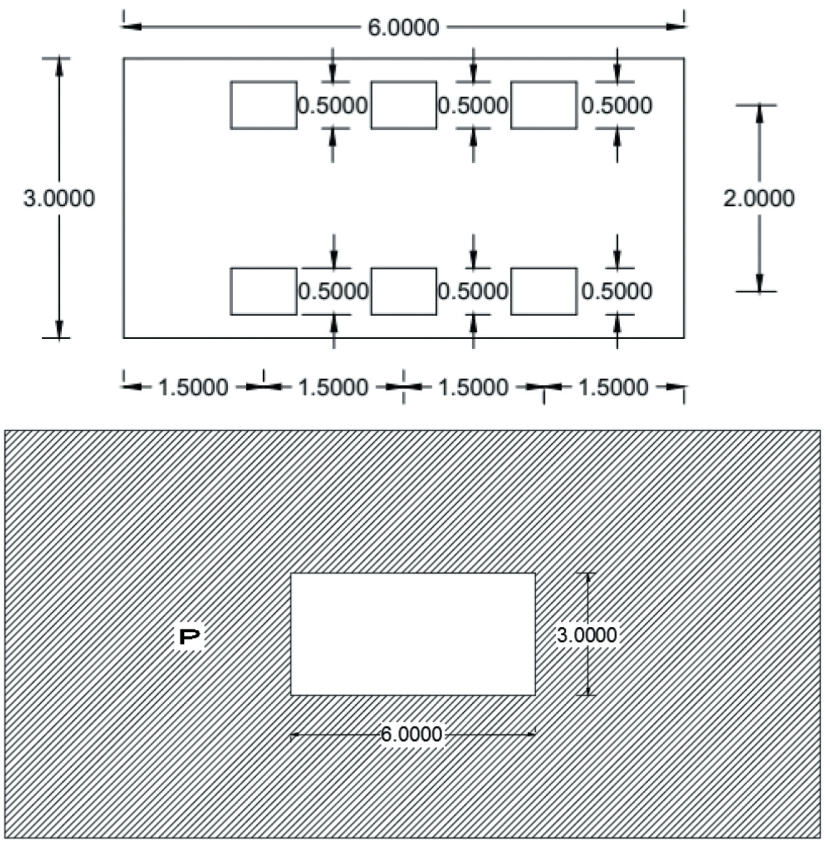

Fig. 2 Loading on the bridge

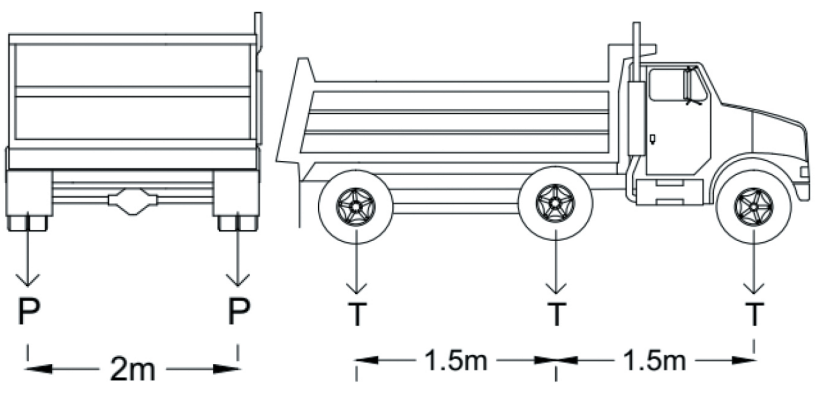

Fig. 3 Model of the TB-45 vehicle 


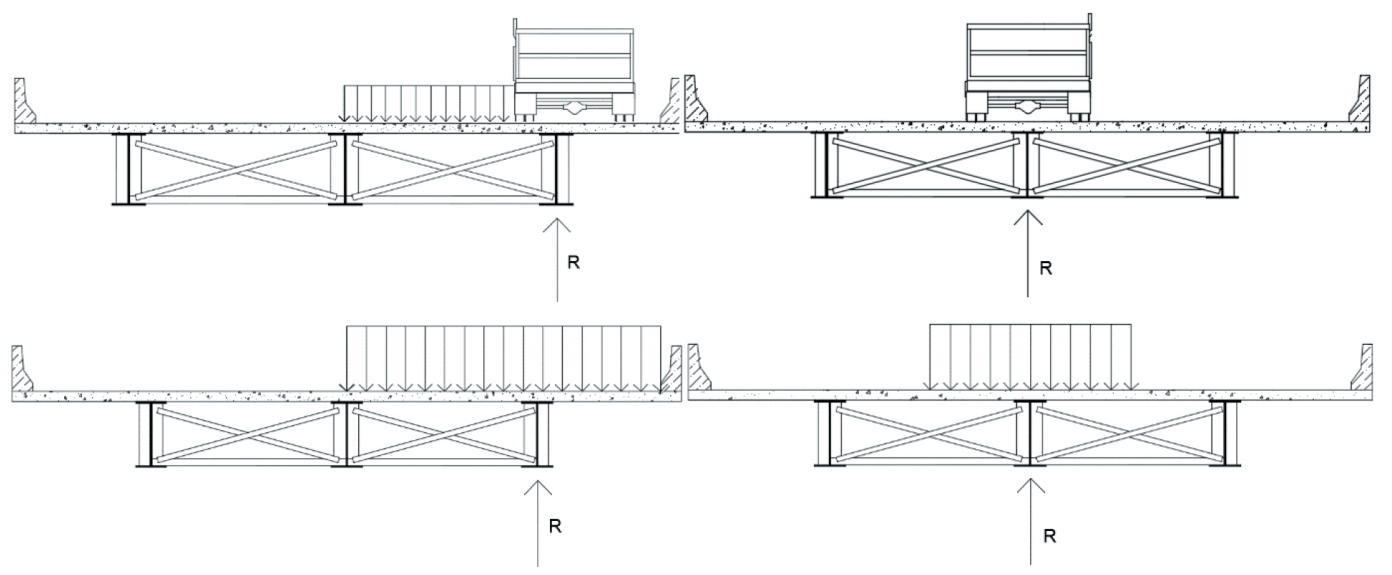

Fig. 4 Reaction of the girders

\subsection{Objective function}

In optimization, the aim can be weight reduction, cost reduction, or both at the same time. It means that researchers can optimize their own structures based on reduction of weight or cost or both. Here; the goal is to minimize the material cost. The objective function is expressed as:

$\min \operatorname{cost}=c_{\text {con }}+c_{b}+c_{d i f}+c_{l}+c_{s t}+c_{s s}+c_{\text {stud }}+c_{\text {rein }}$,

where cost is the total cost. Here, $c_{c o n}, c_{b}, c_{d i f}, c_{l}, c_{s t}, c_{s s}$, $c_{\text {rein }}$ and $c_{\text {stud }}$ are the concrete cost, girder cost, diaphragm cost, longitudinal stiffener cost, transversal stiffener cost, support stiffener cost, stud cost, and reinforcement cost, respectively.

\subsection{Constraints}

Different types of constraints are considered in this section.

\subsubsection{Reinforcement}

Reinforcement constraints consist of the following:

$g_{1}=1-\left[\frac{A_{s}}{\frac{M}{f_{y} \times(d-(0.4 \times N A))}}\right] \leq 0$,

$g_{2}=1-\frac{A_{s, \min }}{0.002 \times 100 \times h_{c}} \leq 0$,

$g_{3}=1-\left[\frac{67}{A_{l}}\right] \leq 0$.

$A_{s}$ is the area of the reinforcement section; $f_{y}$ is the yield strength of steel; $d$ is the distance from compression face to centroid of tension reinforcement; $N A$ is the neutral axis of the section, and $M$ is the maximum bending moment on the slab. If concrete slab is placed on three or more supports, moment due to live load is multiplied by $0.8 . A_{l}$ is the longitudinal reinforcement.

\subsubsection{Girders}

For girders the constraints are expressed as:

$g_{4}=1-\left[\frac{\left(0.55 \times f_{y}\right)}{f_{b t}}\right] \leq 0$,

$g_{5}=1-\left[\frac{\left(0.55 \times f_{y}\right)}{f_{b b}}\right] \leq 0$,

$g_{6}=1-\left[\frac{\left(0.33 \times f_{y}\right)}{f_{v}}\right] \leq 0$,

$g_{7}=1-\left[\frac{\left(0.40 \times f_{c}^{\prime}\right)}{f_{c}}\right] \leq 0$.

$f_{b t}$ is the maximum stress on the top flange; $f_{b b}$ is the maximum stress on the bottom flange; $f_{v}, f_{c}$, and $f_{c}{ }^{\prime}$ are the maximum stresses on the beam web, slab, and the 28-day compressive concrete strength, respectively.

\subsubsection{Deflection}

For deflection, the constraint is expressed as:

$g_{8}=1-\left[\frac{\left(\frac{L}{800}\right)}{\Delta}\right] \leq 0$.

$L$ is the span length, and $\Delta$ is the maximum deflection. 


\subsubsection{Studs}

For studs, we should have:

$$
\begin{aligned}
& g_{9}=1-\left[\frac{h_{\text {stud }}}{4 \times d_{\text {stud }}}\right] \leq 0, \\
& g_{10}=1-\left[\frac{\left(2.5 \times t_{t}\right)}{d_{\text {stud }}}\right] \leq 0 .
\end{aligned}
$$

$h_{\text {stud }}, d_{\text {stud }}$, and $t_{t}$ are the height of the stud, diameter of the stud, and top flange thickness, respectively. Due to many deformation cycles, studs are determined based on fatigue considerations.

\subsubsection{Support stiffener}

For support stiffeners we should have:

$g_{11}=1-\left[\frac{\left(\frac{b_{t}-t_{w}}{2}\right)}{b_{s s}}\right] \leq 0$,

$g_{12}=1-\left[\frac{t_{s s}}{\frac{b_{s s}}{12} \sqrt{\frac{f_{y}}{22.8}}}\right] \leq 0$,

$$
\left\{\begin{array}{l}
g_{13}=1-\left[\frac{F_{s s}}{\frac{V}{A_{s s}}}\right] \leq 0 \\
A_{s s}=\left(b_{s s} \times t_{s s} \times 2\right)+\left(18 \times t_{w}^{2}\right)
\end{array} .\right.
$$

$b_{t}$ and $F_{s s}$ are the beam top flange width and the stiffener allowable stress, respectively. $V$ is the design shear force on the support. $b_{s s}, t_{s s}$, and $t_{w}$ are the width and thickness of the support stiffener and the beam web thickness, respectively.

\subsubsection{Transversal stiffener}

For the following equations to be satisfied, using transversal stiffeners is necessary.

$$
\left\{\begin{array}{l}
t_{w} \leq \frac{h_{v}}{150} \\
f_{v} \geq F_{v e} \\
F_{v e} \leq F_{v}=0.33 \times f_{y} \\
F_{v e}=\frac{50500\left(\frac{K N}{\mathrm{~cm}^{2}}\right)}{\left[\frac{h_{v}}{t_{w}}\right]^{2}}
\end{array}\right.
$$

$h_{v}$ is the beam web height; $F_{v}$ is the allowable shear stress on the beam web, and $F_{v e}$ is the shear force on the transversal stiffener. When using transversal stiffeners, we should have:

$g_{14}=1-\left[\frac{b_{s t}}{\left(5+\frac{h_{v}}{30}\right)}\right] \leq 0$,

$g_{15}=1-\left[\frac{b_{s t}}{\frac{b_{t}}{4}}\right] \leq 0$,

$g_{16}=1-\left[\frac{t_{s t}}{\frac{b_{s t}}{16}}\right] \leq 0$

$\left\{\begin{array}{l}g_{17}=1-\left[\frac{A_{s t}}{A_{\text {st.min }}}\right] \leq 0 \\ A_{\text {st.min }}=\left[0.15 \times B \times \frac{h_{v}}{t_{w}}(1-c) \frac{f_{v}}{F_{v}}-18\right] \frac{f_{y}}{F_{c r}} t_{w}^{2}\end{array}\right.$,

$\left\{\begin{array}{l}g_{18}=1-\left[\frac{I_{s t}}{I_{s t . m i n}}\right] \leq 0 \\ I_{s t . \text { min }}=d_{s t} \times t_{w}^{3} \times J \\ J=2.5\left(\frac{h_{v}}{d s t}\right)^{2}-2 \geq 0.5\end{array}\right.$,

$$
F_{c r}=\frac{6222\left(\frac{\mathrm{kN}}{\mathrm{cm}}\right)}{\left(\frac{b_{s t}}{t_{s t}}\right)^{2}} .
$$


$b_{s t}, t_{s t}, A_{s t}, A_{s t . m i n}, I_{s t}$, and $I_{s t . m i n}$ are the width, thickness, section area, minimum section area, inertia, and minimum inertia of the stiffener, respectively. Here, $B$ and $c$ are coefficients that are 1 for pair transversal stiffener on both sides of the web. $d_{s t}$ is the distance between transversal stiffeners.

\subsubsection{Longitudinal stiffener}

For the following equations to be satisfied, using transversal stiffeners is necessary.

$$
\left\{\begin{array}{l}
t_{w} \leq \frac{h_{v}}{170} \\
t_{w} \leq h_{v} \frac{\sqrt{\frac{f_{b s}}{1\left(\frac{K N}{c m^{2}}\right)}}}{600}
\end{array} .\right.
$$

When using transversal stiffeners we should have:

$g_{19}=1-\left[\frac{t_{w}}{\sqrt{\frac{f_{b s}}{1\left(\frac{K N}{c m^{2}}\right)}}}\right] \leq 0$,

$g_{20}=1-\left[\frac{t_{w}}{\frac{h_{v}}{340}}\right] \leq 0$,

$$
g_{21}=1-\left[\frac{b_{s l}}{\left(5+\frac{h_{v}}{30}\right)}\right] \leq 0,
$$

$$
g_{22}=1-\left[\frac{b_{s l}}{\frac{b_{s}}{4}}\right] \leq 0
$$

$$
g_{23}=1-\left[\frac{t_{s l}}{\frac{b_{s l}}{16}}\right] \leq 0,
$$

$$
\begin{aligned}
& g_{24}=1-\left[\frac{I_{s l}}{I_{s l . m i n}}\right] \leq 0 \\
& I_{s l \text { min }}=h_{v} \times t_{w}^{3} \times\left[2.4 \frac{d_{s t}^{2}}{h_{v}^{2}}-0.13\right]
\end{aligned}
$$

$b_{s l}, t_{s l}, I_{s l}$, and $I_{s l \text { min }}$ are the width, thickness, inertia, and minimum inertia of the longitudinal stiffener, respectively.

\subsubsection{Diaphragm}

$g_{25}=1-\left[\frac{n_{\text {dif }}}{\left[\left(\text { round } \frac{L}{7.6}\right)+1\right]}\right] \leq 0$,

$g_{26}=1-\left[\frac{r_{d i f}}{\left(\frac{1}{2} \times \frac{s}{120}\right)}\right] \leq 0$,

$g_{27}=1-\left[\frac{r_{d i f}}{\frac{\sqrt{s^{2}+\left(t_{t}+h_{v}+t_{b}\right)^{2}}}{200}}\right] \leq 0$.

$n_{d i f}, r_{d i f}$, and $s$ are the number of diaphragms, the radius of gyration of the diaphragm, and the width between girders, respectively. $g_{1}$ to $g_{27}$ are constraints of this problem.

\section{Penalty function}

When the constraints are not satisfied, in iterations, the penalty function must be applied to the problem. If $g_{i}>0, i=1$, $2, \ldots, 27$, it means that a constraint is not satisfied. Therefore, a penalty function is introduced as follows:

$$
\begin{aligned}
& P_{T}(x)=\left[1+\varepsilon_{1} \cdot\left(\sum_{i=1}^{27} p_{i}(x)\right)\right], \\
& p_{i}(x)=\max \left(0, g_{i}(x)\right), i=1,2, \ldots, 27 .
\end{aligned}
$$

$P_{T}(x)$ is the penalty function and $\varepsilon_{1}$ is the penalty parameter that is considered as 10 to reject those designs that do not meet the safety conditions or make the search too time consuming. The objective function stated in Eq. (2) is penalized by this penalty function.

\section{Colliding Bodies Optimization Algorithm}

This algorithm was developed by Kaveh and Mahdavi [1]. The main idea of this algorithm is based on the rules of momentum and one dimensional collision of bodies from 

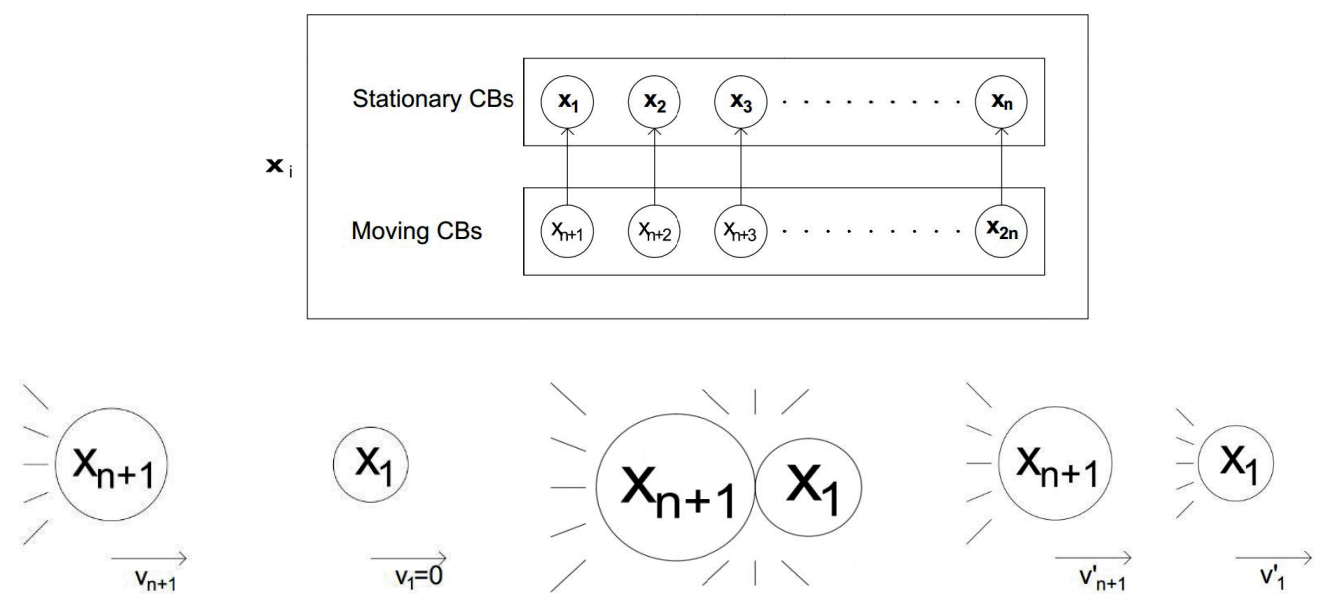

Fig. 5 The collision between two bodies

Physics. The colliding bodies optimization is based on momentum and energy conservation law for one-dimensional collision. This algorithm is used for both discrete and continuous variable problems.

In colliding bodies' algorithm, each agent is modeled as a body that has self-specific mass and velocity. Collision between bodies and moving them to the minimum level energy is the main purpose in the procedure of this algorithm. If on a system, external force is not applied and this system is isolated, the momentum of all bodies after collision will be equal to the momentum of all bodies before collision. The colliding bodies' algorithm, at first, considers a set of colliding bodies (CB). Each body can be considered as a solution illustrated by $X_{i}$. The magnitude of the body mass for each $\mathrm{CB}$ is defined as:

$m_{k}=\frac{\frac{1}{f i t(k)}}{\sum_{i=1}^{n} \frac{1}{f i t(k)}} k=1,2, \ldots, 2 n$

fit $(i)$ represents the objective function value of the agent $i ; n$ is the population size. In the first iteration, an initial population is created randomly. Then, CBs are sorted according to their objective function and in a descending order. CBs are divided into two groups of stationary bodies and moving bodies. Moving bodies move toward stationary bodies and create collision. This is done for two purposes: 1. to improve the positions of moving bodies and 2. to push stationary bodies towards better positions. New positions of these bodies, are updated according to their new velocities. Colliding bodies and their procedure are illustrated in Fig. 5. The velocity of stationary and moving bodies before collision is calculated as:
$V_{i}=0, \mathrm{i}=1,2, \ldots, n$

$V_{i}=x_{i-n}-x_{i}, i=n+1, n+2, \ldots, 2 n$

$V_{i}$ and $x_{i}$ are the velocity and position vector of the $i$ th $\mathrm{CB}$ in this group, respectively. $2 n$ is the population size. The velocity of the stationary and moving bodies after collision is calculated as:

$$
\begin{aligned}
& V_{i}^{\prime}=\frac{\left(m_{i}+\varepsilon m_{i+n}\right) V_{i+n}}{m_{i}+m_{i+n}}, i=1,2, \ldots, n, \\
& V_{i}^{\prime}=\frac{\left(m_{i}-\varepsilon m_{i-n}\right) V_{i}}{m_{i}+m_{i-n}}, i=n+1, n+2, \ldots, 2 n, \\
& \varepsilon=1-\frac{i t e r}{i t e r_{\text {max }}} .
\end{aligned}
$$

$\varepsilon$ is the coefficient of restitution (COR). The coefficient of restitution (COR) is used to control the exploration and exploitation rates. When COR is considered as unity, the CBs investigate the entire search space to discover a favorite space (global search) and the algorithm converges very slow. On the other hand, when COR is selected as zero, the movements of the CBs are confined to very small space in order to provide exploitation (local search) and the algorithm converges very fast. In order to avoid these problems, we used $\mathrm{COR}=\varepsilon$. In this way a good balance between the global search and local search is achieved. Here, iter is the

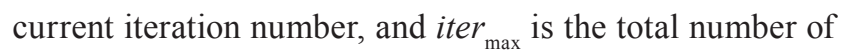
iterations for the optimization process. The new position of bodies after collision is determined as:

$X_{i}^{\text {new }}=X_{i}+$ rand $\circ V_{i}^{\prime}, i=1,2, \ldots, n$, 


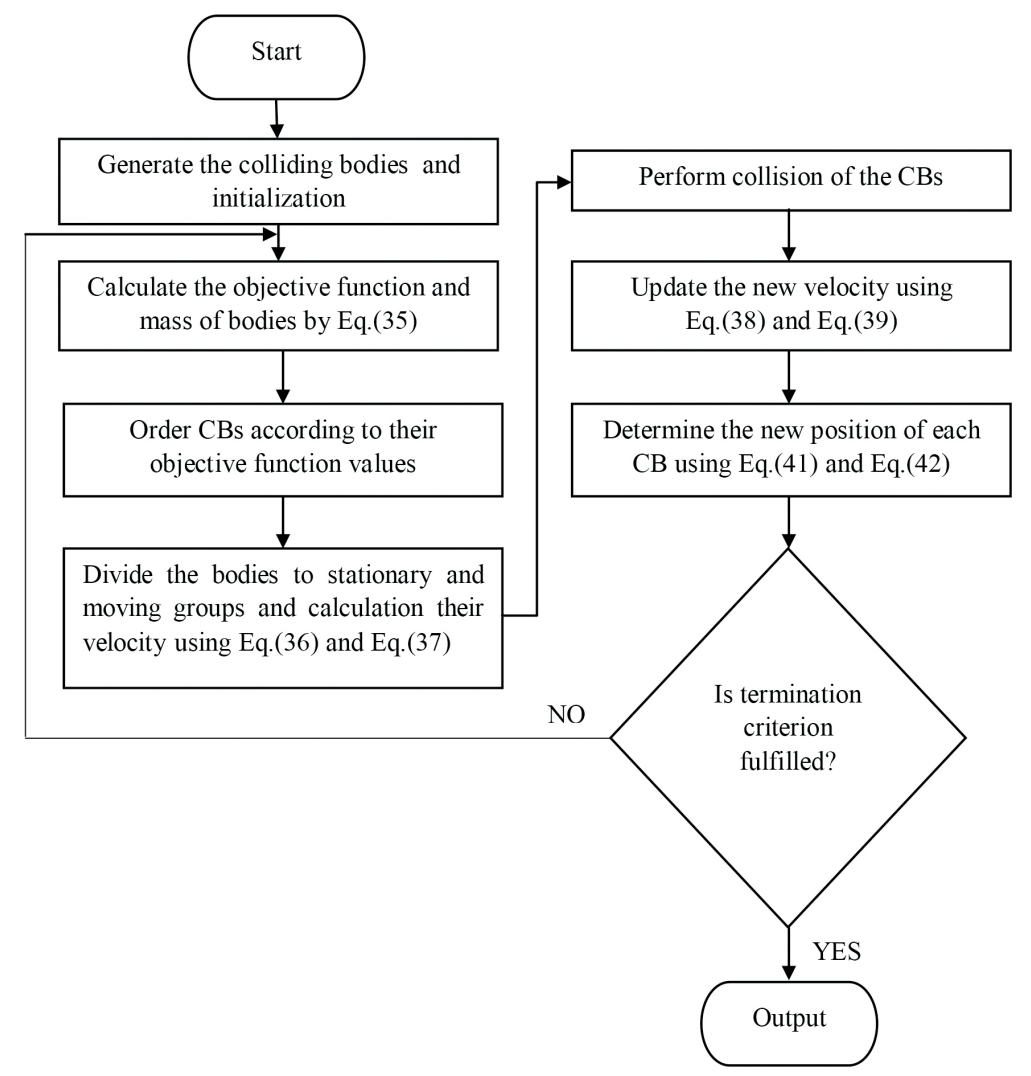

Fig. 6 Flowchart of the $\mathrm{CBO}$

$X_{i}^{\text {new }}=X_{i-n}+\operatorname{rand} \odot V_{i}^{\prime}, i=n+1, n+2, \ldots, 2 n \quad$.

$X_{i}^{\text {new }}$ and $V_{i}^{\prime}$ are the new position and the new velocity after the collision of the $i$ th $\mathrm{CB}$, respectively. Here, rand is a random vector uniformly distributed in the range of $[0,1]$. The sign "O" denotes an element-by-element multiplication. The flowchart of the CBO algorithm is shown in Fig. 6. While stopping criterion is not satisfied, the iterations continue. This stopping criterion can be an objective-related condition or can be considered as a pre-defined number of iterations. Ultimately, the procedure summary is provided in the following:

Step 1: Initialize and create the initial population;

Step 2: Calculate the objective functions;

Step 3: Sort the bodies according to their objective function;

Step 4: Divide the bodies to stationary and moving groups and calculate their velocity;

Step 5: Collision between bodies;

Step 6: Calculate the new velocity of stationary and moving bodies by Eq. (38) and Eq. (39);

Step 7: Calculate the new position of stationary and moving bodies by Eq. (41) and Eq. (42);

Step 8: Check the stopping criterion;
Step 9: If the stopping criterion is satisfied, go to the next step; otherwise, return to Step 2, considering new amounts;

Step 10: Present the best results from total iterations.

\section{Enhanced Colliding Bodies Optimization}

This algorithm was first introduced by Kaveh and Ilchi Ghazaan [2]. High performance of this algorithm is shown by different applications Kaveh and Ilch Ghazaan [38]. $\mathrm{ECBO}$ is similar to $\mathrm{CBO}$, both being based on the rule of one-dimensional collision of bodies, and the difference between these algorithms is due to the addition of a memory in ECBO. Addition of such a memory increases the convergence speed, and makes the algorithm able to escape local optima. From physics the momentum can be written as:

$P=m v$,

where $m$ is the mass, and $v$ is the velocity. In an isolate system that does not exchange any matter with its surroundings, and is not acted on by external forces, the total momentum is constant. The law of conservation of momentum is illustrated in Fig. 7. Both objects in this figure have the same mass. 
1)<smiles>CC(C)(C)C1CCCCC1</smiles>

2)

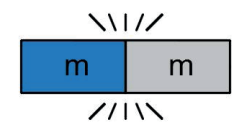

3)

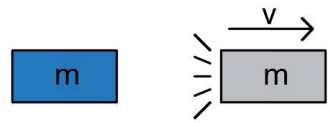

Fig. 7 The law of momentum

The collision between the bodies changes the velocity and position of the stationary and moving bodies. Initial position of bodies is determined randomly as follows:

$X_{i}^{0}=X_{\min }+$ rand. $\left(X_{\max }+X_{\min }\right), i=1,2,3, \ldots, 2 n$.

$X_{i}^{0}$ is the initial solution vector of the $i$ th CB. $X_{\min }$ is the minimum allowable limits vector, and $X_{\max }$ is the maximum allowable limits vector. A collision memory (CM) is used to save the best previous answers. In each iteration, solution vectors saved in $\mathrm{CB}$ are added to the population, and the same number of the worst colliding bodies $(\mathrm{CB})$ is removed. The flowchart of the ECBO algorithm is shown in Fig. 8. The procedure summary is provided in the following:
Step 1: Initialize and create the initial population;

Step 2: Calculate the objective function;

Step 3: Save some historically best $\mathrm{CB}$ vectors and their related mass, and objective function values in $\mathrm{CM}$ and add solution vectors saved in CM to the population, delete the same number of current worst CBs in each iteration and the same number of current worst CBs is deleted in each iteration

Step 4: Sort the bodies according to their objective function

Step 5: Divide the bodies to stationary and moving group and calculate their velocity by Eq. (36) and Eq. (37).

Step 6: Collision between bodies;

Step 7: Calculate the new velocity of stationary and moving bodies by Eq. (38) and Eq. (39);

Step 8: Calculate the new position of stationary and moving bodies by Eq. (41) and Eq. (42);

Step 9: Introduce a parameter like Pro within $(0,1)$ which specifies whether a component of each $\mathrm{CB}$ must be changed or not;

Step 10: Check the stopping criterion;

Step 11: If the stopping criterion is satisfied, go to the next step; otherwise, return to Step 2 considering new amounts;

Step 12: Present the best results from total iterations.

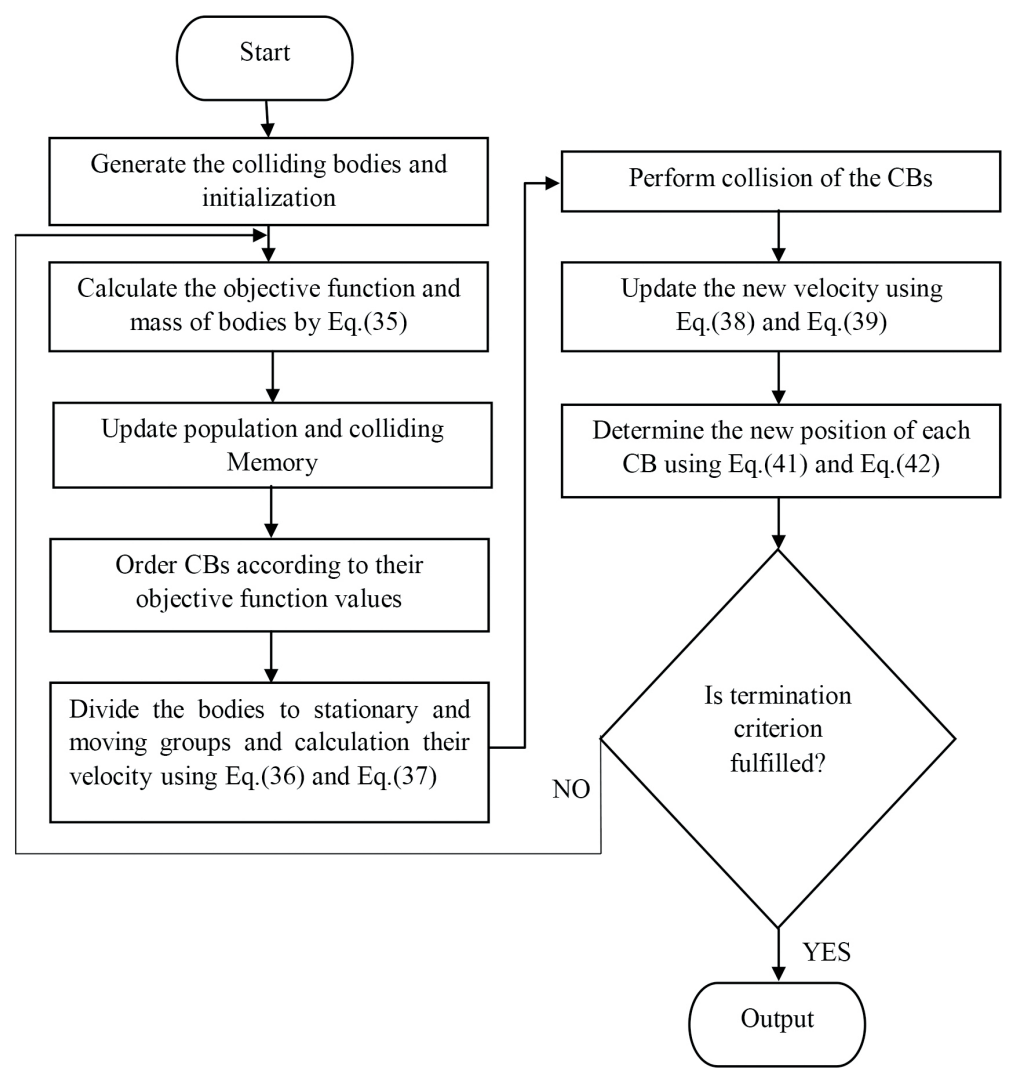

Fig. 8 Flowchart of the ECBO 


\section{Vibrating Particles System}

Vibrating particles system (VPS) was developed by Kaveh and Ilchi Ghazaan [3]. This algorithm simulates the free vibration of single degree of freedom systems with viscous damping. Kaveh and Ilch Ghazaan [38] illustrated the high performance of this algorithm for large scale and complex structures in their studies. A new enhanced version of the VPS is presented in the recent book [38]. In this algorithm, some particles are considered as variables of the problem. These particles are initialized randomly, and then they gradually approach their equilibrium positions. Initial position of each particle is created randomly in an n-dimensional search space.

$$
X_{i}^{j}=X_{\min }+\operatorname{rand} .\left(X_{\max }-X_{\min }\right) .
$$

$X_{i}^{j}, X_{\min }$, and $X_{\max }$ are, respectively, the $j$ th variable of particle $i$, the minimum allowable variable bound vector, and the maximum allowable variable bound vector.

VPS considers each solution candidate as a particle. For each particle, three equilibrium positions are considered with different masses in the process of each iteration: 1 . The historically best position of the entire population (HB); 2. A bad particle (BP); and 3. A good particle (GP). In each iteration, the objective function is calculated for all particles. Particles are sorted incrementally. These particles are divided into two equal groups. The GP is selected from the first group and the BP is selected from the second group, randomly. In order to update the new position of particles, this equation is used:

$$
\begin{aligned}
& X_{i}^{j}=w_{1} \cdot\left[\text { D.A.rand } 1+H B^{j}\right]+w_{2} \cdot\left[\text { D.A.rand } 2+G P^{j}\right] \\
& +w_{3} \cdot\left[\text { D.A.rand } 3+B P^{j}\right] \\
& D=\left(\frac{\text { iter }}{\text { iter }_{\max }}\right)^{-a}, \\
& A=\left[w_{1} \cdot\left(H B^{j}-X_{i}^{j}\right)\right]+\left[w_{2} \cdot\left(G P^{j}-X_{i}^{j}\right)\right] \\
& +\left[w_{3} \cdot\left(B P^{j}-X_{i}^{j}\right)\right] \\
& w_{1}+w_{2}+w_{3}=1 .
\end{aligned}
$$

iter and iter $_{\max }$ are the current iteration number and the total number of iterations for the optimization process, respectively. $\alpha$ is a constant. The effect of $\alpha$ is illustrated in Fig. 9. $w_{1}, w_{2}$, and $w_{3}$ are three parameters to measure the relative importance of $\mathrm{HB}, \mathrm{GP}$, and BP, respectively. rand 1 , rand 2 , and rand 3 are random numbers uniformly distributed in the range of $[0,1]$. A parameter like $p$ within $(0,1)$ is defined for each particle. If $p<$ rand, $w_{3}=0$, and $w_{2}=1-w_{1}$, then the effect of BP is ignored in updating the position formula. The flowchart of the VPS algorithm is shown in Fig. 10. The procedure of the algorithm is as follows:

Step 1: Parameters of the problem are considered, and the positions of the particles are determined randomly.

Step 2: Objective function of particles are calculated.

Step 3: Positions of particles are updated by Eq. (46).

Step 4: Constraints are checked.

Step 5: Stopping criterion is checked.

Step 6: If the stopping criterion is satisfied, it goes to next step; otherwise, it returns to step 2 considering new amounts.

Step 7: It presents the best results from total iterations.

\section{Numerical studies}

In this section, first the variables are defined and then the numerical results are presented. Here, according to search space and observations from preliminary optimization runs, the number of iterations is determined to be 2000 . The parameters utilized for each optimization algorithm are shown in Table 1. In order to have a better comparison between our new algorithms and one of excellent previous algorithm, Particle swarm optimization (PSO) is used. PSO is a population-based stochastic optimization algorithm that has been successfully used to solve many optimization problems [39]. Though the PSO has been widely utilized to address various complicated engineering problems, it is likely to suffer lack of diversity and ineffectiveness of balance between the global search ability and the local search ability in the search process [40]. The flowchart of PSO is shown in Fig 11. [41]

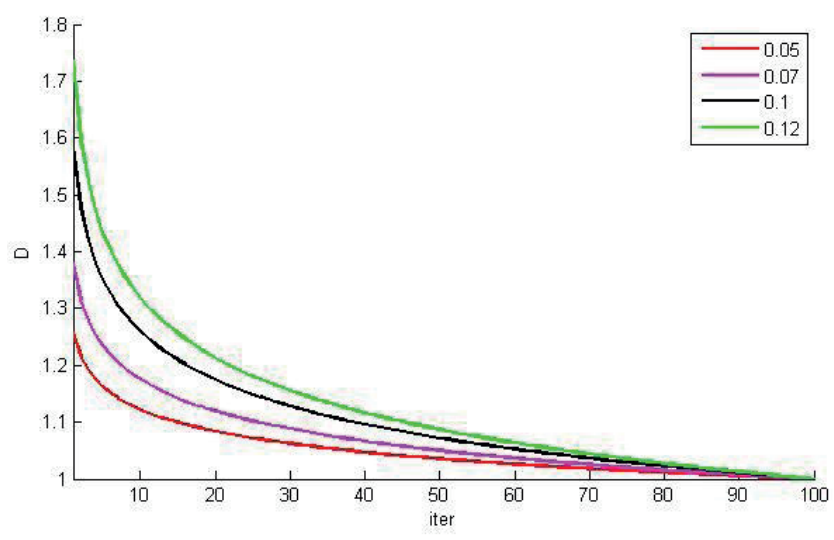

Fig. 9 The influence of $\alpha$ on the D function 


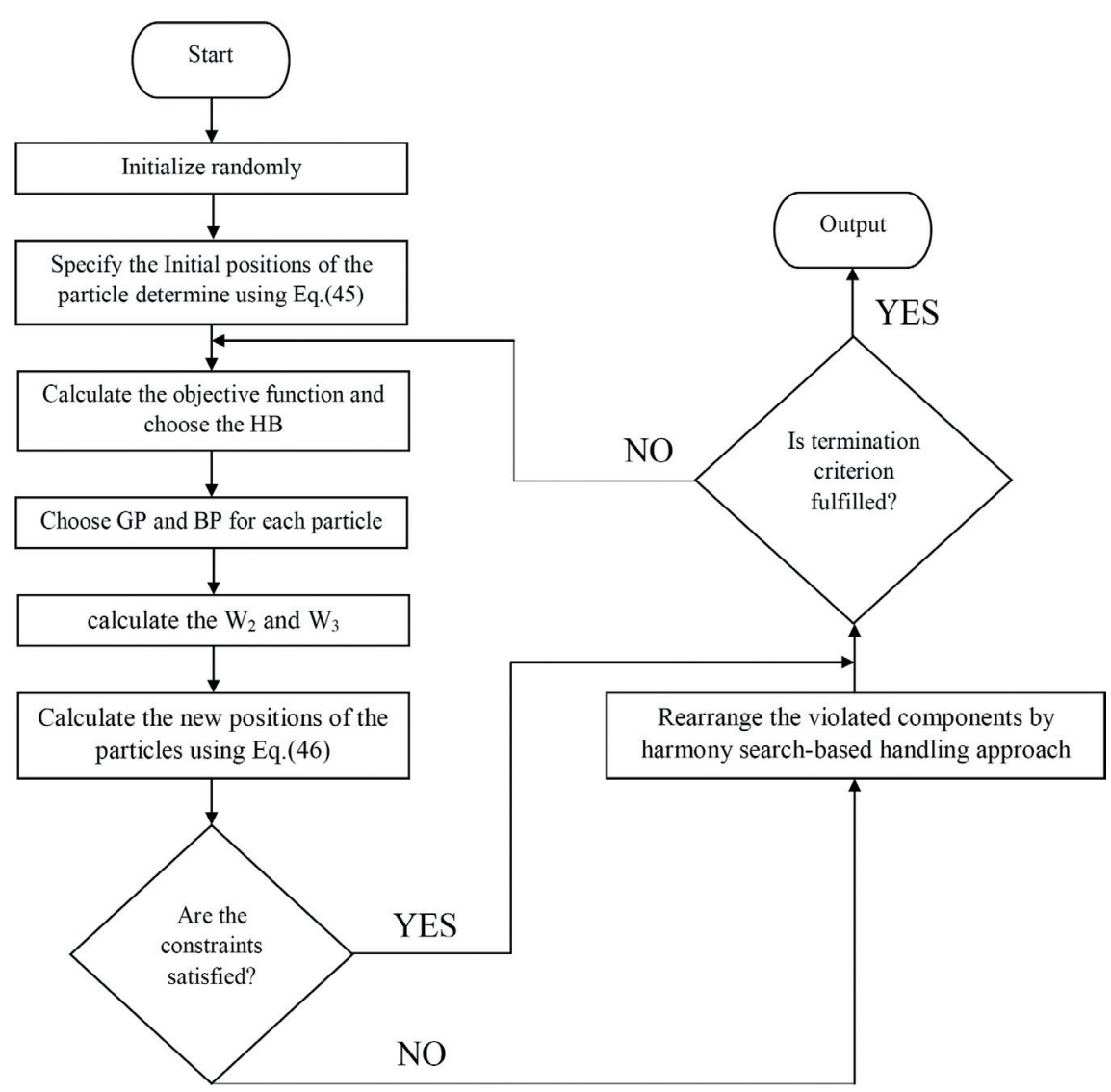

Fig. 10 Flowchart of the VPS

Table 1 Algorithms Parameters

\begin{tabular}{cccc}
\hline CBO & ECBO & VPS & PSO \\
\hline & & Pop.size $=30-32$ \\
maxIt $=2000$ & Pop.size $=30-32$ \\
Pop.size $=30-32$ & alfa $1=1$ & maxIt $=2000$ \\
maxIt $=2000$ & maxIt $=2000$ & beta $1=0.05$ & phi $1=2.05$ \\
Inf $=1$ e100 & $\mathrm{CMs}=4=0.3$ & phi $2=2.05$ \\
& pro $=0.2-0.3-0.4$ & $\mathrm{C} 2=0.3$ & wdamp $=1$ \\
& stoch $=0.7$ & \\
& par $=0.1$ & \\
& cmcr $=0.95$ & \\
& neighboring $=0.1$ &
\end{tabular}

\subsection{Design variables}

Variables of the present optimization problem are divided into two groups consisting of continuous variables and discrete variables. In this study, continuous variables are considered for reinforcements, and discrete variables are used as the distance between girders, dimensions of girders, dimension of stiffeners, dimension of stud connectors, and the type of concrete and steel. This problem has 26 variables; three variables are continuous, and 23 variables are discrete. All variables are presented in Table 2. These variables are illustrated in Fig. 12. Some parameters of this problem are taken as constant in the process of optimization such as the width of the bridge (13 m), its length (30, 40 and $50 \mathrm{~m})$, and geometry of the bridge which are not considered as variables.

Group 1: Increases from lower bound to upper bound at increments of $25 \mathrm{~cm}$.

Group 2: Increases from lower bound to upper bound at $1 \mathrm{~cm}$ increments.

Group 3: Intermediate values are imposed by the industry catalogue between the lower bound and upper bound

Group 4: Increases from the lower bound to upper bound at 1 unit increments. 


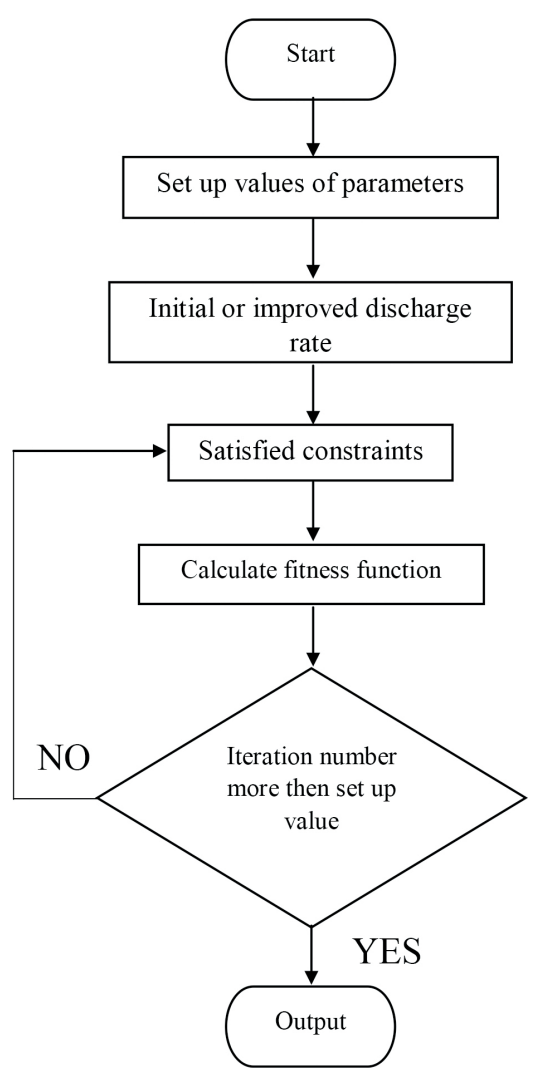

Fig. 11 Flowchart of the PSO $n b$ and $n$ diaf are the number of girders and diaphragms, respectively. The industrial values between the lower and upper bounds are given in Table 3. These prices are obtained by IBGE (Brazilian Institute of Statistics and Geography) every month in Brazil along with a survey of costs of civil construction conducted by Caixa (Federal Economic Fund) [42]. The data (from June, 2015) are provided in Table 4 . The prices are converted to dollars with the exchange rate of 19 November 2015, which has been $\mathrm{R} \$ 3.75$ [20].

\subsection{Results for 4-girders}

In this section, the results of optimal design of four girders are presented. In order to compare the results of this study with those of the manual design [20], four girders are used. The results are provided in Table 5, where it is shown that the calculated cost of VPS algorithm is less than those of the $\mathrm{CBO}$ and $\mathrm{ECBO}$. Moment and shear on each girder form these results, as given in Table 6, indicating that optimal design from $\mathrm{ECBO}$ has moment and shear values less than those corresponding to the other optimal designs. In Table 6 , there are two costs. One of these is the cost in dollars and the other cost is in Brazilian Reals. Here, the distances between the four girders are considered as $3.5 \mathrm{~m}$, and the
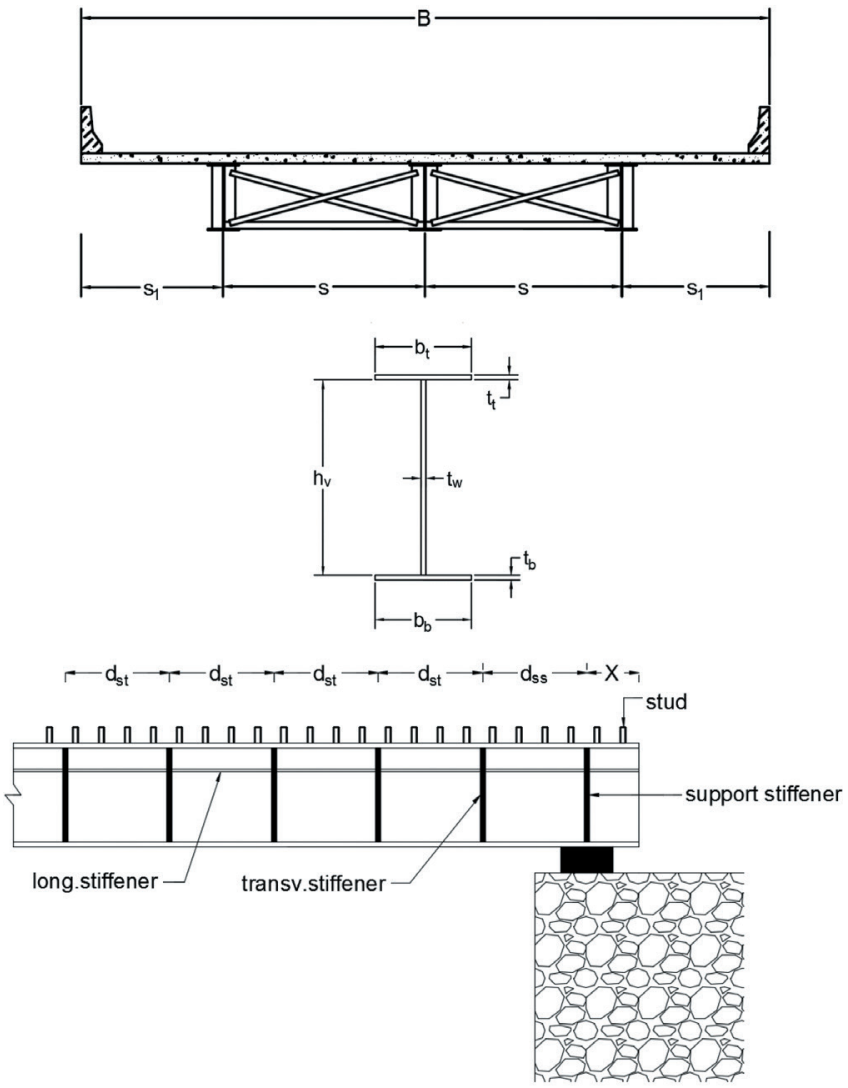

Fig. 12 Details of the bridge 
Table 2 Optimization variables and their boundary conditions

\begin{tabular}{|c|c|c|c|c|c|}
\hline Type & Group & Variable & Unit & Lower bound & Upper bound \\
\hline \multirow{4}{*}{ Continuous } & - & Long. Positive Reinf & $\mathrm{cm}^{2}$ & 0.1 & 20 \\
\hline & - & Long. Negative Reinf & $\mathrm{cm}^{2}$ & 0.1 & 20 \\
\hline & - & Transv. Positive Reinf & $\mathrm{cm}^{2}$ & 0.1 & 20 \\
\hline & 1 & $s$ & $\mathrm{~m}$ & 2 & 4 \\
\hline \multirow{22}{*}{ Discrete } & 2 & $h_{c}$ & $\mathrm{~cm}$ & 20 & 25 \\
\hline & 2 & $b_{t}$ & $\mathrm{~cm}$ & 30 & 100 \\
\hline & 2 & $h_{v}$ & $\mathrm{~cm}$ & 100 & 200 \\
\hline & 2 & $b_{b}$ & $\mathrm{~cm}$ & 30 & 100 \\
\hline & 2 & $h_{\text {stud }}$ & $\mathrm{cm}$ & 1 & 15 \\
\hline & 2 & $b_{s s}$ & $\mathrm{~cm}$ & 10 & 50 \\
\hline & 2 & $b_{s t}$ & $\mathrm{~cm}$ & 10 & 100 \\
\hline & 2 & $d_{s s}$ & $\mathrm{~cm}$ & 10 & 300 \\
\hline & 2 & $d_{s t}$ & $\mathrm{~cm}$ & 10 & 300 \\
\hline & 2 & $b_{s l}$ & $\mathrm{~cm}$ & 10 & 100 \\
\hline & 3 & conrete & - & $\mathrm{C}-20$ & C-35 \\
\hline & 3 & $t_{t}$ & $\mathrm{~cm}$ & 0.95 & 10.16 \\
\hline & 3 & $t_{w}$ & $\mathrm{~cm}$ & 0.95 & 10.16 \\
\hline & 3 & $t_{b}$ & $\mathrm{~cm}$ & 0.95 & 10.16 \\
\hline & 3 & $d_{\text {stud }}$ & $\mathrm{cm}$ & 1.9 & 2.5 \\
\hline & 3 & $t_{s s}$ & $\mathrm{~cm}$ & 0.95 & 10.16 \\
\hline & 3 & $t_{s t}$ & $\mathrm{~cm}$ & 0.95 & 10.16 \\
\hline & 3 & $t_{s l}$ & $\mathrm{~cm}$ & 0.95 & 10.16 \\
\hline & 3 & diaf & $\mathrm{mm}$ & $101 * 101 * 6.35$ & $152 * 152 * 19.05$ \\
\hline & 4 & $n b$ & - & 3 & 6 \\
\hline & 4 & ndiaf & - & 1 & 30 \\
\hline & - & steel & - & A36 & A572 Gr50 \\
\hline
\end{tabular}

Table 3 The industrial values

\begin{tabular}{lr}
\hline Variable & Values between lower and upper bound \\
\hline Concrete & C-20 $;$ C-25; C-30 $;$ C-35 \\
Thickness & $0.95 ; 1.11 ; 1.27 ; 1.43 ; 1.59 ; 1.75 ; 1.9 ; 2.06 ; 2.22 ; 2.38 ; 2.54 ; 2.86 ; 3.18 ; 3.49 ; 3.81 ; 4.12 ; 4.44 ; 4.76 ; 5.08 ; 5.4 ; 5.71 ; 6.03 ;$ \\
& $6.35 ; 6.66 ; 6.98 ; 7.3 ; 7.62 ; 10.16(\mathrm{~cm})$ \\
Diaphragm & $\mathrm{L} 101.6 \times 6.35 ; \mathrm{L} 101.6 \times 7.93 ; \mathrm{L} 101.6 \times 9.52 ; \mathrm{L} 101.6 \times 11.11 ; \mathrm{L} 101.6 \times 12.7 ; \mathrm{L} 127 \times 6.35 ; \mathrm{L} 127 \times 7.94 ; \mathrm{L} 127 \times 9.52 ; \mathrm{L} 127 \times 12.7 ; \mathrm{L} 127 \times 15.88 ;$ \\
& $\mathrm{L} 127 \times 11.11 ; \mathrm{L} 152.4 \times 9.52 ; \mathrm{L} 152.4 \times 12.7 ; \mathrm{L} 152.4 \times 15.88 ; \mathrm{L} 152.4 \times 19.05(\mathrm{~mm})$
\end{tabular}

width of the cantilevered section is considered as $1.25 \mathrm{~m}$. Results of 36 runs are illustrated in Table 7. In this study, all of algorithms are run 36 times and according to the corresponding results, Table 7 is formed. The convergence curves of all the algorithms are demonstrated in Fig. 13. This figure shows a better performance for the VPS algorithm. Results of 36 independent runs with their best solutions for the considered girders are depicted in Fig. 14. Normal distribution curves are shown in Fig. 15. $69 \%$ of results of $\mathrm{CBO}, 67 \%$ of results of $\mathrm{ECBO}$ and $69 \%$ of results of VPS are located between 140,000-150,000 (U\$). Since the curve for the VPS has higher elongation, therefore the results of 36 runs of this algorithm have higher distribution and non-normal distribution curve is shown in Fig. 16. This figure illustrates the data distribution of 36 runs of each algorithm.

\subsection{Results of general state}

This section presents the results of the optimization without considering the constraints of Section 8.2. Results of optimal design are provided in Table 8. This table shows that VPS decreases the cost of the structures considerably. Reduction of the number of girders can be effective in decreasing the cost. In this table, there are two costs. One is the cost in dollars and the other cost is in Brazilian Reals. Moment and shear on each girder are provided in 


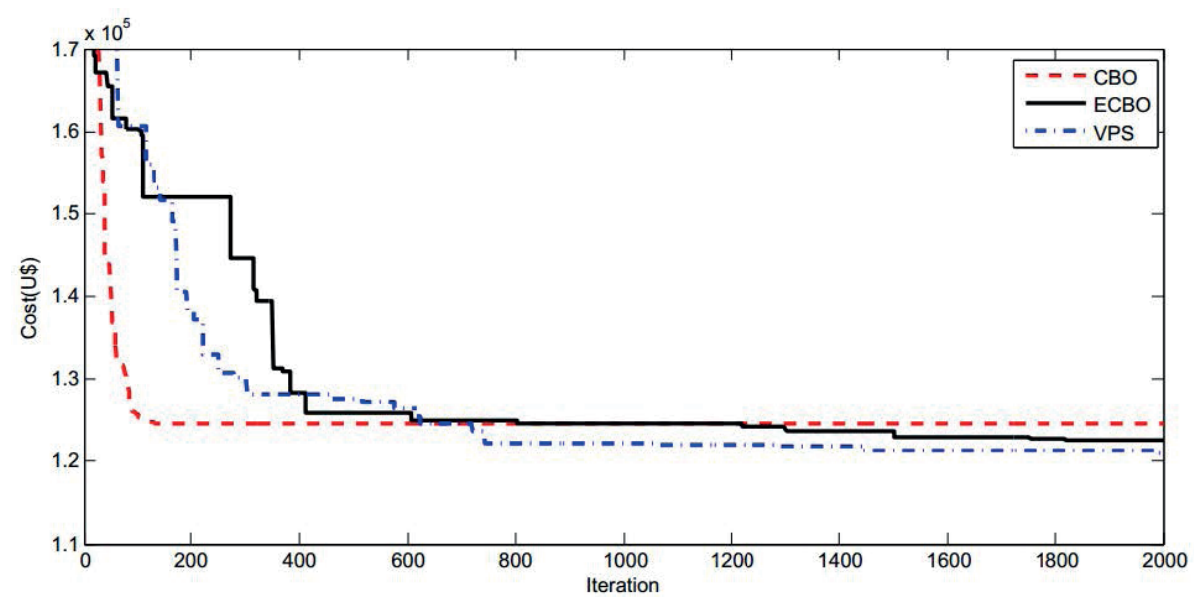

Fig. 13 Convergence curves of the 4-girders

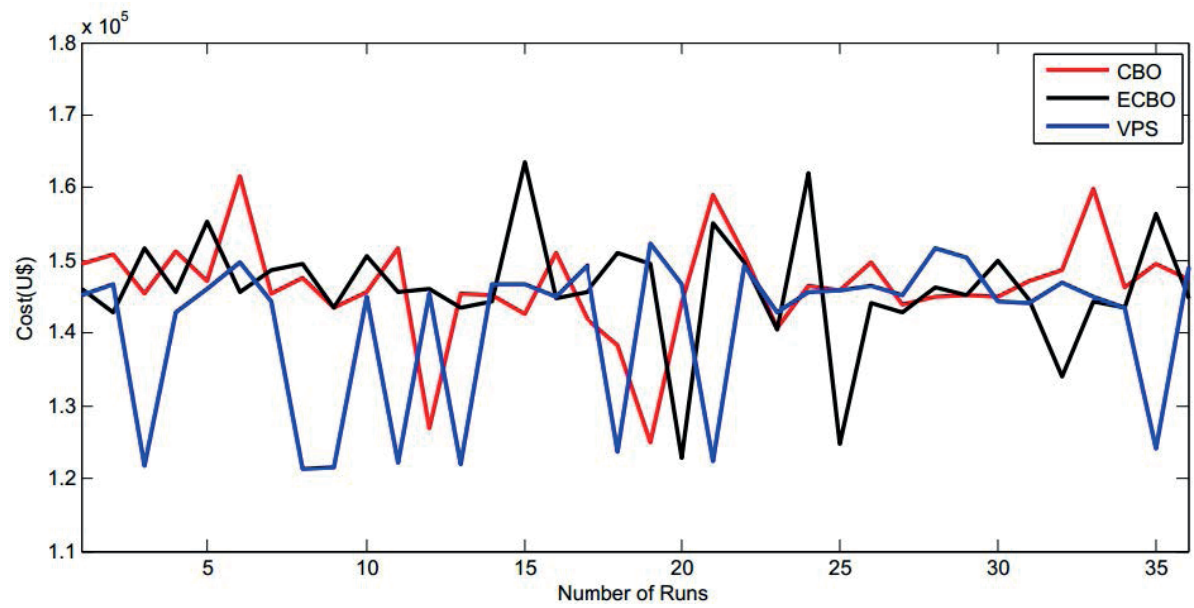

Fig. 14 Optimum cost of 36 independent runs of the 4 -girders
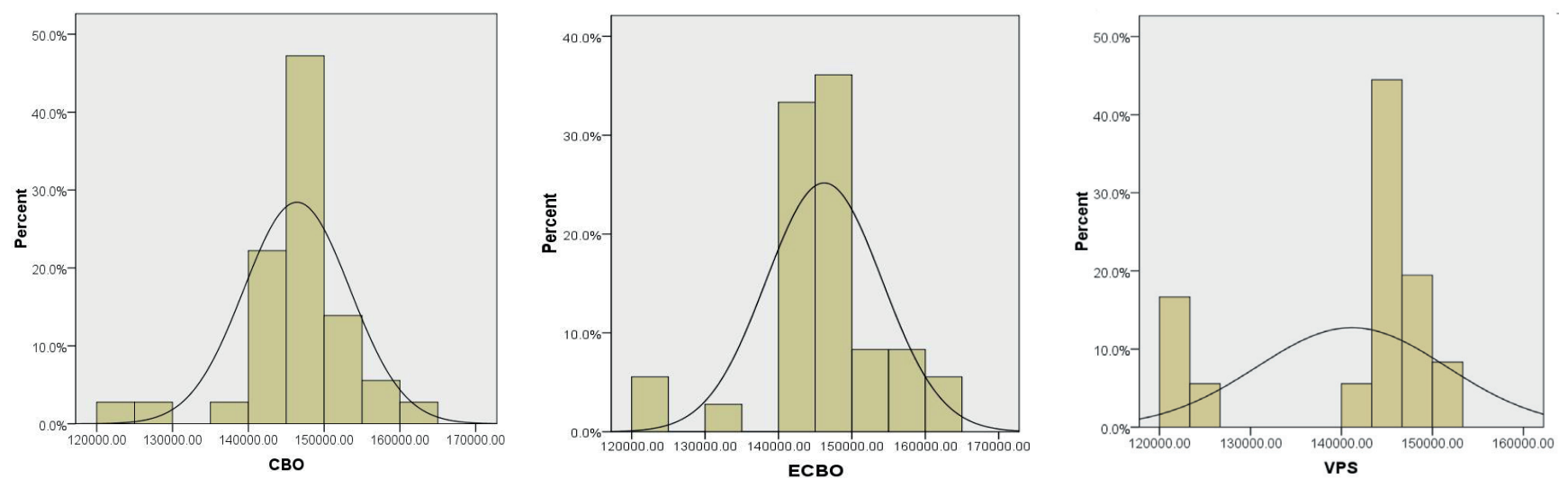

Fig. 15 Normal distributions curves of 36 runs of the 4-girders

Table 4 List of the prices

\begin{tabular}{lccc}
\hline Items & Unit & Price (U\$) & Price (R\$) \\
\hline Steel ASTM A36 & $\mathrm{kg}$ & 1.09 & 4.08 \\
Steel ASTM A572 Gr.50 & $\mathrm{kg}$ & 1.21 & 4.54 \\
Reinforcement steel & $\mathrm{kg}$ & 1.66 & 6.22 \\
Concrete C-20 & $\mathrm{m} 3$ & 93.65 & 351.20 \\
Concrete C-25 & $\mathrm{m} 3$ & 97.07 & 364.03 \\
Concrete C-30 & $\mathrm{m} 3$ & 99.92 & 374.71 \\
Concrete C-35 & $\mathrm{m} 3$ & 103.06 & 386.46 \\
\hline
\end{tabular}


Table 5 Numerical results of the 4-girders

\begin{tabular}{|c|c|c|c|c|}
\hline \multirow{2}{*}{ Variable } & \multirow{2}{*}{ Manual [22] } & \multicolumn{3}{|c|}{ New algorithms } \\
\hline & & $\mathrm{CBO}$ & ECBO & VPS \\
\hline$s$ & $3.5 \mathrm{~m}$ & $3.5 \mathrm{~m}$ & $3.5 \mathrm{~m}$ & $3.5 \mathrm{~m}$ \\
\hline$s_{1}$ & $1.25 \mathrm{~m}$ & $1.25 \mathrm{~m}$ & $1.25 \mathrm{~m}$ & $1.25 \mathrm{~m}$ \\
\hline concrete & C-25 & C-35 & $\mathrm{C}-25$ & C-30 \\
\hline steel & A572 Gr.50 & A572 Gr.50 & A572 Gr.50 & A572 Gr.50 \\
\hline$n b$ & 4 & 4 & 4 & 4 \\
\hline Long. Positive Reinf & $8.00 \mathrm{~cm}^{2}$ & $8.1 \mathrm{~cm}^{2}$ & $11.3 \mathrm{~cm}^{2}$ & $17.5 \mathrm{~cm}^{2}$ \\
\hline Long. Negative Reinf & $13.00 \mathrm{~cm}^{2}$ & $9.4 \mathrm{~cm}^{2}$ & $12.5 \mathrm{~cm}^{2}$ & $8.5 \mathrm{~cm}^{2}$ \\
\hline Transv. Positive Reinf & $5.00 \mathrm{~cm}^{2}$ & $4.5 \mathrm{~cm}^{2}$ & $5.6 \mathrm{~cm}^{2}$ & $5.8 \mathrm{~cm}^{2}$ \\
\hline$h_{c}$ & $23 \mathrm{~cm}$ & $23 \mathrm{~cm}$ & $21 \mathrm{~cm}$ & $20 \mathrm{~cm}$ \\
\hline$b_{t}$ & $50 \mathrm{~cm}$ & $98 \mathrm{~cm}$ & $59 \mathrm{~cm}$ & $64 \mathrm{~cm}$ \\
\hline$h_{v}$ & $193 \mathrm{~cm}$ & $196 \mathrm{~cm}$ & $196 \mathrm{~cm}$ & $196 \mathrm{~cm}$ \\
\hline$b_{b}$ & $67 \mathrm{~cm}$ & $60 \mathrm{~cm}$ & $90 \mathrm{~cm}$ & $53 \mathrm{~cm}$ \\
\hline$h_{\text {stud }}$ & $15 \mathrm{~cm}$ & $15 \mathrm{~cm}$ & $11 \mathrm{~cm}$ & $11 \mathrm{~cm}$ \\
\hline$b_{s s}$ & $20 \mathrm{~cm}$ & $13 \mathrm{~cm}$ & $16 \mathrm{~cm}$ & $18 \mathrm{~cm}$ \\
\hline$b_{s t}$ & $17 \mathrm{~cm}$ & $25 \mathrm{~cm}$ & $16 \mathrm{~cm}$ & $17 \mathrm{~cm}$ \\
\hline$b_{s l}$ & $17 \mathrm{~cm}$ & - & - & - \\
\hline$t_{t}$ & $2.54 \mathrm{~cm}$ & $0.95 \mathrm{~cm}$ & $1.75 \mathrm{~cm}$ & $1.59 \mathrm{~cm}$ \\
\hline$t_{w}$ & $0.95 \mathrm{~cm}$ & $1.43 \mathrm{~cm}$ & $1.43 \mathrm{~cm}$ & $1.43 \mathrm{~cm}$ \\
\hline$t_{b}$ & $5.08 \mathrm{~cm}$ & $4.76 \mathrm{~cm}$ & $3.18 \mathrm{~cm}$ & $5.4 \mathrm{~cm}$ \\
\hline$d_{\text {stud }}$ & $2.2 \mathrm{~cm}$ & $2.2 \mathrm{~cm}$ & $2.2 \mathrm{~cm}$ & $2.2 \mathrm{~cm}$ \\
\hline$t_{s s}$ & $2.22 \mathrm{~cm}$ & $1.9 \mathrm{~cm}$ & $1.75 \mathrm{~cm}$ & $1.9 \mathrm{~cm}$ \\
\hline$t_{s t}$ & $1.27 \mathrm{~cm}$ & $1.59 \mathrm{~cm}$ & $1.11 \mathrm{~cm}$ & $1.11 \mathrm{~cm}$ \\
\hline$t_{s l}$ & $1.27 \mathrm{~cm}$ & - & - & - \\
\hline diaf & $127 \times 127 \times 9.52 \mathrm{~mm}$ & $101.6 \times 101.6 \times 6.35 \mathrm{~mm}$ & $101.6 \times 101.6 \times 7.93 \mathrm{~mm}$ & $101.6 \times 101.6 \times 6.35 \mathrm{~mm}$ \\
\hline ndiaf & 7 & 7 & 7 & 7 \\
\hline Cost (U\$) & $128,700.35$ & $124,985.88$ & $122,744.37$ & $121,201.17$ \\
\hline Cost $(\mathrm{R} \$)$ & $482,626.31$ & $468,697.05$ & 460291.38 & $454,504.38$ \\
\hline reduction & $0 \%$ & $2.88 \%$ & $4.62 \%$ & $5.82 \%$ \\
\hline
\end{tabular}

Table 6 Maximum actions on the girder

\begin{tabular}{lccc}
\hline Actions & CBO & ECBO & VPS \\
\hline Moment & $13011.55 \mathrm{kN} . \mathrm{m}$ & $13104.21 \mathrm{kN} . \mathrm{m}$ & $12894.24 \mathrm{kN} . \mathrm{m}$ \\
Shear & $1325.55 \mathrm{kN}$ & $1335.25 \mathrm{kN}$ & $1313.90 \mathrm{kN}$ \\
\hline
\end{tabular}

Table 9, which illustrate that optimal design from ECBO has moment and shear values less than other designs. Results of the 36 runs are given in Table 10. The convergence histories of all the utilized algorithms are demonstrated in Fig. 17. Results presented are those of the best solutions from the 36 runs. These results reveal that ECBO has a better performance compared to CBO and VPS. Results of the 36 independent runs are illustrated in Fig. 18. Normal distribution curves are shown in Fig. 19. 48 \% of the results of the CBO are located between 140000 and 150000 (U\$), for ECBO this amount is $35 \%$, and $49 \%$ of the results of the VPS are located in this area. This figure shows that the results of the 36 runs of the VPS have higher distribution than $\mathrm{CBO}$, and ECBO has non-normal distribution as shown in Fig. 20.

Table 11 shows that cost of the construction according to different length spans. In this table, two population sizes (Pop. size) are considered (pop30 and pop32). A comparative study is performed for three spans $(30 \mathrm{~m}, 40 \mathrm{~m}, 50 \mathrm{~m})$ with two different populations sizes. Fig. 21 illustrates the convergence curves related to three spans (30 m, $40 \mathrm{~m}, 50 \mathrm{~m})$ with population size equal 30, and Fig. 22 shows that same convergence curves related to three spans $(30 \mathrm{~m}, 40 \mathrm{~m}, 50 \mathrm{~m})$ but with a population size of 32 . It should also be noted that the result is improved for ECBO with population size equal 32 for span $50 \mathrm{~m}$. Amounts of population sizes are decided based on experience. All the algorithms are run 36 times to find the best amount of population sizes. 
Table 7 Results for 36 runs of the 4 -girders

\begin{tabular}{lccccc}
\hline Item & $\mathrm{N}$ & Minimum (U\$) & Maximum (U\$) & Median (U\$) & Std. Deviation \\
\hline CBO & 36 & 124985.88 & 161680.70 & 146412.82 & 7014.75 \\
ECBO & 36 & 122744.37 & 163500.96 & 146223.37 & 7922.39 \\
VPS & 36 & 121201.17 & 152280.54 & 141151.83 & 10430.20 \\
\hline
\end{tabular}

Table 8 Numerical results of the general state

\begin{tabular}{|c|c|c|c|c|c|}
\hline \multirow{2}{*}{ Variable } & \multirow{2}{*}{ Manual [22] } & \multirow{2}{*}{ PSO } & \multicolumn{3}{|c|}{ New algorithms } \\
\hline & & & $\mathrm{CBO}$ & ECBO & VPS \\
\hline$s$ & $3.5 \mathrm{~m}$ & $3.25 \mathrm{~m}$ & $3.25 \mathrm{~m}$ & $3.5 \mathrm{~m}$ & $4 \mathrm{~m}$ \\
\hline$s_{1}$ & $1.25 \mathrm{~m}$ & $1.625 \mathrm{~m}$ & $1.625 \mathrm{~m}$ & $1.25 \mathrm{~m}$ & $2.5 \mathrm{~m}$ \\
\hline concrete & $\mathrm{C}-25$ & $\mathrm{C}-25$ & $\mathrm{C}-35$ & $\mathrm{C}-25$ & C-35 \\
\hline steel & A572 Gr.50 & A36 & A36 & A572 Gr.50 & A572 Gr.50 \\
\hline$n b$ & 4 & 4 & 4 & 4 & 3 \\
\hline Long. Positive Reinf & $8.00 \mathrm{~cm}^{2}$ & $6.6 \mathrm{~cm}^{2}$ & $7.4 \mathrm{~cm}^{2}$ & $7.7 \mathrm{~cm}^{2}$ & $11.8 \mathrm{~cm}^{2}$ \\
\hline Long. Negative Reinf & $13.00 \mathrm{~cm}^{2}$ & $6.6 \mathrm{~cm}^{2}$ & $7.4 \mathrm{~cm}^{2}$ & $7.7 \mathrm{~cm}^{2}$ & $13.9 \mathrm{~cm}^{2}$ \\
\hline Transv. Positive Reinf & $5.00 \mathrm{~cm}^{2}$ & $3.1 \mathrm{~cm}^{2}$ & $4.3 \mathrm{~cm}^{2}$ & $3.3 \mathrm{~cm}^{2}$ & $5.4 \mathrm{~cm}^{2}$ \\
\hline$h_{c}$ & $23 \mathrm{~cm}$ & $22 \mathrm{~cm}$ & $20 \mathrm{~cm}$ & $20 \mathrm{~cm}$ & $21 \mathrm{~cm}$ \\
\hline$b_{t}$ & $50 \mathrm{~cm}$ & $59 \mathrm{~cm}$ & $58 \mathrm{~cm}$ & $79 \mathrm{~cm}$ & $46 \mathrm{~cm}$ \\
\hline$h_{v}$ & $193 \mathrm{~cm}$ & $176 \mathrm{~cm}$ & $197 \mathrm{~cm}$ & $195 \mathrm{~cm}$ & $196 \mathrm{~cm}$ \\
\hline$b_{b}$ & $67 \mathrm{~cm}$ & $63 \mathrm{~cm}$ & $47 \mathrm{~cm}$ & $74 \mathrm{~cm}$ & $62 \mathrm{~cm}$ \\
\hline$h_{\text {stud }}$ & $15 \mathrm{~cm}$ & $8 \mathrm{~cm}$ & $9 \mathrm{~cm}$ & $8 \mathrm{~cm}$ & $14 \mathrm{~cm}$ \\
\hline$b_{s s}$ & $20 \mathrm{~cm}$ & $16 \mathrm{~cm}$ & $10 \mathrm{~cm}$ & $11 \mathrm{~cm}$ & $14 \mathrm{~cm}$ \\
\hline$b_{s t}$ & $17 \mathrm{~cm}$ & $15 \mathrm{~cm}$ & $15 \mathrm{~cm}$ & $20 \mathrm{~cm}$ & $12 \mathrm{~cm}$ \\
\hline$b_{s l}$ & $17 \mathrm{~cm}$ & - & - & - & - \\
\hline$t_{t}$ & $2.54 \mathrm{~cm}$ & $2.38 \mathrm{~cm}$ & $1.43 \mathrm{~cm}$ & $1.27 \mathrm{~cm}$ & $3.49 \mathrm{~cm}$ \\
\hline$t_{w}$ & $0.95 \mathrm{~cm}$ & $1.27 \mathrm{~cm}$ & $1.59 \mathrm{~cm}$ & $1.43 \mathrm{~cm}$ & $1.43 \mathrm{~cm}$ \\
\hline$t_{b}$ & $5.08 \mathrm{~cm}$ & $5.4 \mathrm{~cm}$ & $6.03 \mathrm{~cm}$ & $3.81 \mathrm{~cm}$ & $6.03 \mathrm{~cm}$ \\
\hline$d_{\text {stud }}$ & $2.2 \mathrm{~cm}$ & $1.9 \mathrm{~cm}$ & $2.2 \mathrm{~cm}$ & $1.9 \mathrm{~cm}$ & $2.2 \mathrm{~cm}$ \\
\hline$t_{s s}$ & $2.22 \mathrm{~cm}$ & $1.75 \mathrm{~cm}$ & $5.71 \mathrm{~cm}$ & $2.22 \mathrm{~cm}$ & $2.86 \mathrm{~cm}$ \\
\hline$t_{s t}$ & $1.27 \mathrm{~cm}$ & $0.95 \mathrm{~cm}$ & $0.95 \mathrm{~cm}$ & $1.27 \mathrm{~cm}$ & $1.43 \mathrm{~cm}$ \\
\hline$t_{s l}$ & $1.27 \mathrm{~cm}$ & - & - & - & - \\
\hline diaf & $127 \times 127 \times 9.52 \mathrm{~mm}$ & $152.4 \times 152.4 \times 7.9 \mathrm{~mm}$ & $101.6 \times 101.6 \times 6.35 \mathrm{~mm}$ & $101.6 \times 101.6 \times 6.35 \mathrm{~mm}$ & $101.6 \times 101.6 \times 9.52 \mathrm{~mm}$ \\
\hline ndiaf & 7 & 7 & 7 & 7 & 7 \\
\hline Cost (U\$) & $128,700.35$ & $128,142.95(\mathrm{U} \$)$ & $122,408.96$ & $120,148.61$ & $112,832.89$ \\
\hline Cost $(\mathrm{R} \$)$ & $482,626.31$ & $480,536.06$ & $459,033.60$ & $450,557.28$ & $423,123.33$ \\
\hline reduction & $0 \%$ & $0.43 \%$ & $4.88 \%$ & $6.64 \%$ & $12.32 \%$ \\
\hline
\end{tabular}

Table 9 Maximum Actions on the girder of the general state

\begin{tabular}{lcccc}
\hline Actions & CBO & ECBO & VPS & PSO \\
\hline Moment & $13039.72 \mathrm{kN} . \mathrm{m}$ & $12737.33 \mathrm{kN} . \mathrm{m}$ & $16419.20 \mathrm{kN} . \mathrm{m}$ & $13355.05 \mathrm{KN} . \mathrm{m}$ \\
Shear & $1328.51 \mathrm{kN}$ & $1297.85 \mathrm{kN}$ & $1672.66 \mathrm{kN}$ & $1360.52 \mathrm{KN}$ \\
\hline
\end{tabular}

Table 10 Results for 36 runs of the general state

\begin{tabular}{lccccc}
\hline Item & $\mathrm{N}$ & Minimum (U\$) & Maximum (U\$) & Median (U\$) & Std. Deviation \\
\hline CBO & 36 & 122408.96 & 174110.00 & 143793.16 & 10105.64 \\
ECBO & 36 & 120148.61 & 168800.00 & 139901.91 & 11181.61 \\
VPS & 36 & 112822.89 & 154374.43 & 140095.87 & 12291.13 \\
PSO & 36 & 127753.87 & 179375.64 & 149628.55 & 8267.14 \\
\hline
\end{tabular}


Table 11 Cost of different spans

\begin{tabular}{lccccc}
\hline Length of span $(\mathrm{m})$ & Pop. size & CBO & ECBO & VPS & PSO \\
\hline \multirow{2}{*}{30} & 30 & $63,856.58(\mathrm{U} \$)$ & $60,067.89(\mathrm{U} \$)$ & $55,356.81(\mathrm{U} \$)$ & $79,741.46(\mathrm{U} \$)$ \\
& 32 & $69,131.15(\mathrm{U} \$)$ & $68,056.22(\mathrm{U} \$)$ & $58,376.99(\mathrm{U} \$)$ & $72,590.56(\mathrm{U} \$)$ \\
40 & 30 & $122,408.96(\mathrm{U} \$)$ & $120,148.61(\mathrm{U} \$)$ & $112,832.89(\mathrm{U} \$)$ & $128,142.95(\mathrm{U} \$)$ \\
& 32 & $124,990.43(\mathrm{U} \$)$ & $122,852.01(\mathrm{U} \$)$ & $120,045.78(\mathrm{U} \$)$ & $127,477.47(\mathrm{U} \$)$ \\
50 & 30 & $209,911.96(\mathrm{U} \$)$ & $208,228.36(\mathrm{U} \$)$ & $195,398.20(\mathrm{U} \$)$ & $240,342.48(\mathrm{U} \$)$ \\
& 32 & $213,715.06(\mathrm{U} \$)$ & $192,683.07(\mathrm{U} \$)$ & $200,722.64(\mathrm{U} \$)$ & $216,317.13(\mathrm{U} \$)$ \\
\hline
\end{tabular}

Table 12 Cost of the ECBO according to different Pro coefficients with pop. size $=30$

\begin{tabular}{lcccc}
\hline Span $(\mathrm{m})$ & Pro & Cost (U\$) & Std. Deviation & Median (U\$) \\
\hline \multirow{3}{*}{30} & 0.2 & $68,509.59$ & 9115.94 & 78527.07 \\
& 0.3 & $60,067.89$ & 6291.83 & 71251.75 \\
& 0.4 & $64,479.12$ & 7482.60 & 77474.18 \\
40 & 0.2 & $131,180.24$ & 10914.75 & 147459.17 \\
& 0.3 & $120,148.61$ & 11181.61 & 139901.91 \\
& 0.4 & $122,327.40$ & 10703.25 & 143563.32 \\
50 & 0.2 & $208,329.86$ & 15318.28 & 242978.55 \\
& 0.3 & $208,228.36$ & 13500.15 & 235601.75 \\
\hline
\end{tabular}

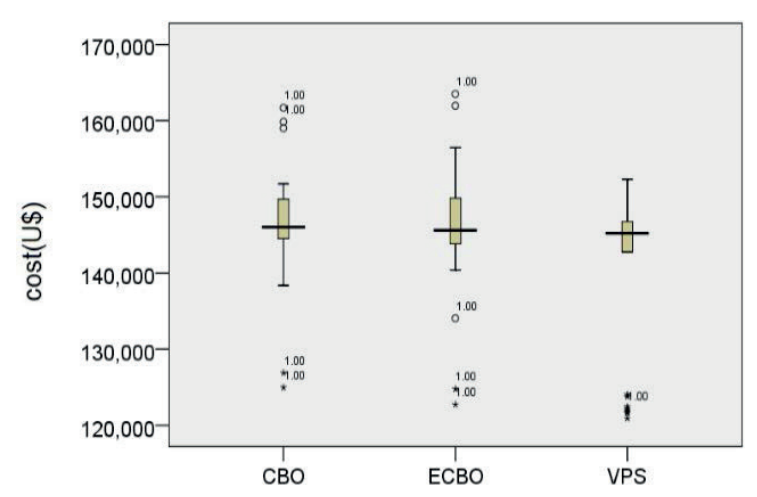

Fig. 16 Non-normal distributions of 36 runs of the 4-girders

Table 12 contains the cost of the bridges with span lengths of $30 \mathrm{~m}, 40 \mathrm{~m}$ and $50 \mathrm{~m}$ obtained by ECBO. Here, three Pro coefficients are considered (Pro $=0.4$, Pro $=$ 0.3 , Pro $=0.2)$ and the minimum cost is obtained. The standard deviation and median of 36 runs, are also illustrated in this table. Pro is a parameter to save the best results from previous iterations. Therefore, if this parameter is selected law or high, it can have unfavorable effect on the process of the ECBO algorithm. Here, by considering three values for the Pro, its best value is determined. To achieve this goal, ECBO with each selected Pro, is run 36 times and the spans are considered as 30 m, $40 \mathrm{~m}$ and $50 \mathrm{~m}$. When Pro was 0.3, the cost of this state is the best solution and the amounts of median of this state was less than other states. The convergence curves for the ECBO in this state are illustrated in Fig. 23.
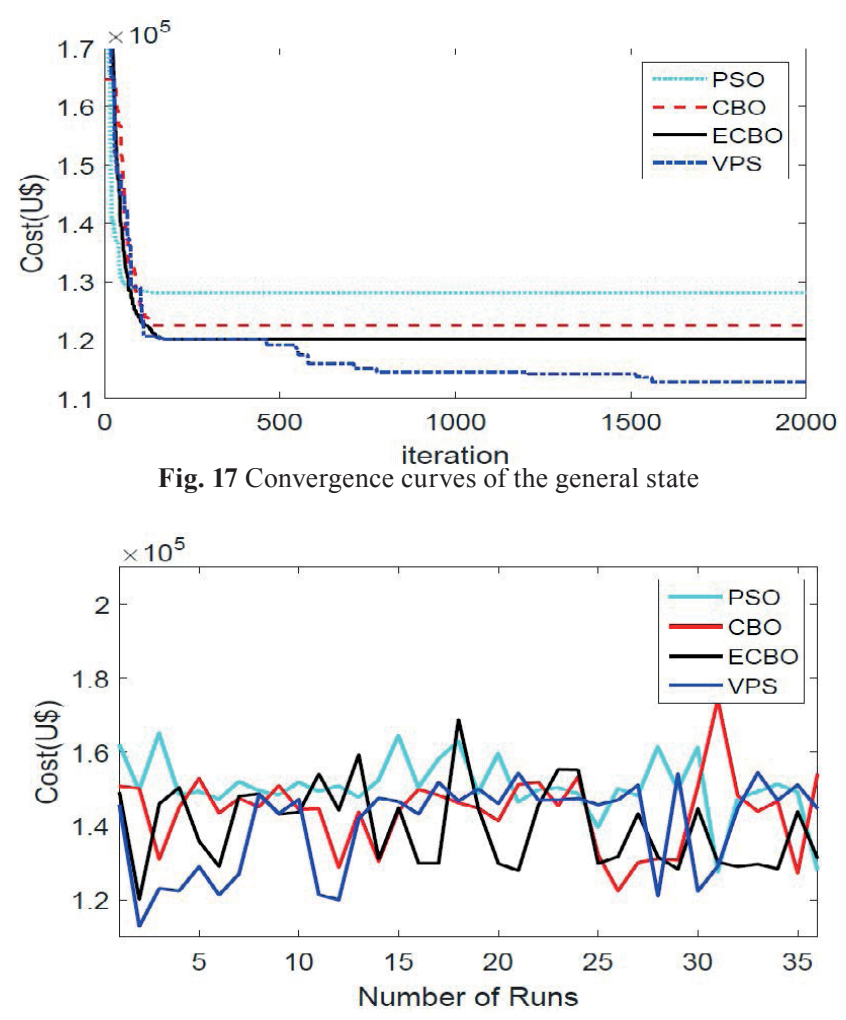

Fig. 18 The optimum cost of 36 independent runs of the general state

\section{Concluions}

This study presents the optimization of steel-concrete I-girder bridges using CBO, ECBO, and VPS. First, three algorithms CBO, ECBO, and VPS were introduced, and then the variables were presented. In this paper, a compar- 

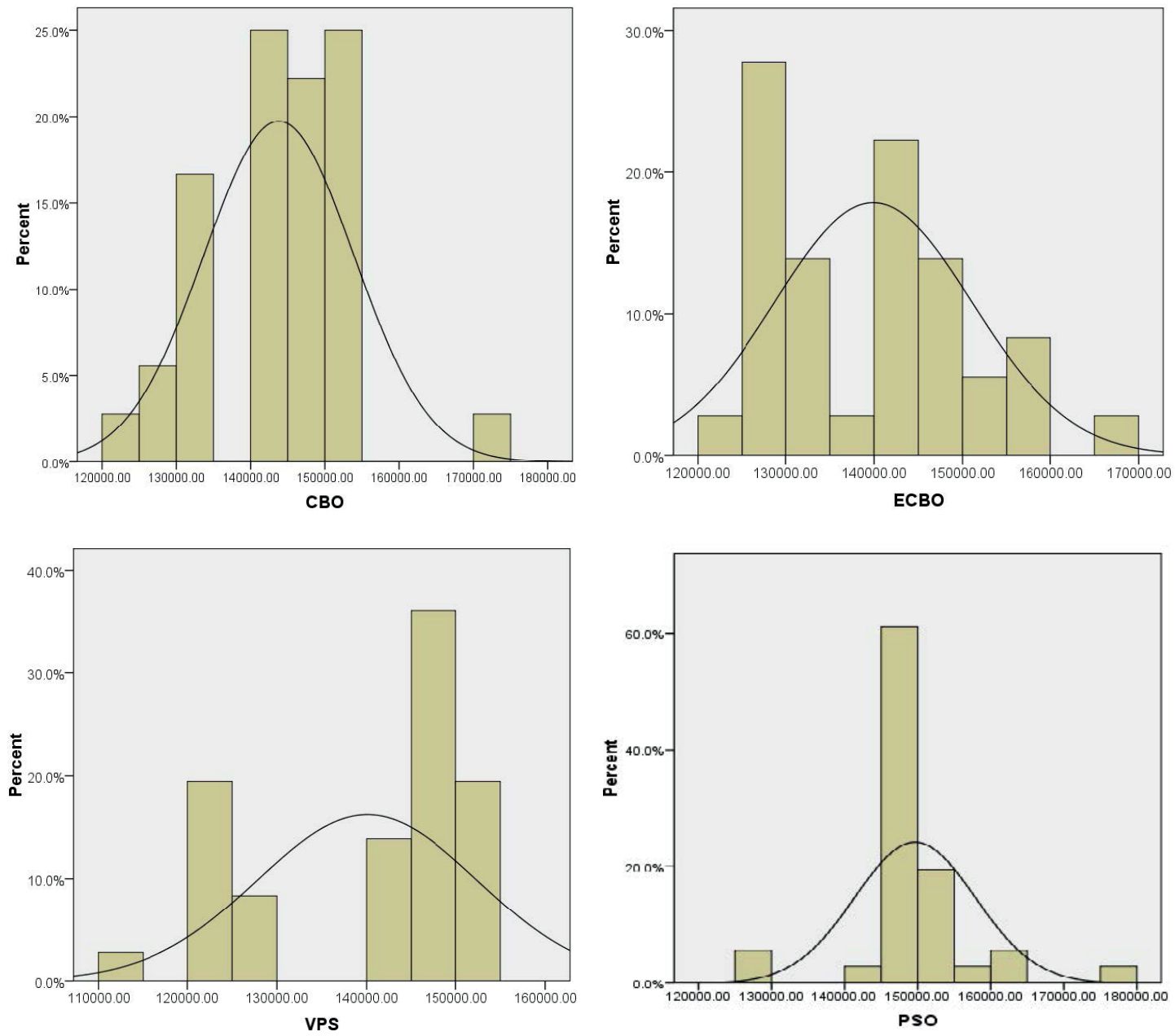

Fig. 19 Normal distributions curves of 36 runs of the general state

ative study is carried out using three new meta-heuristic algorithms. Ultimately, the numerical results indicate the following:

In 4-girder state, $\mathrm{CBO}, \mathrm{ECBO}$ and VPS decrease cost $2.88 \%, 4.62 \%$ and $5.82 \%$ respectively. In this state, moment and shear on girder from optimal design of VPS are $0.9 \%$ and $1.6 \%$ less than moment on girder form optimal design of $\mathrm{CBO}$ and $\mathrm{ECBO}$, respectively.

In general state, $\mathrm{CBO}, \mathrm{ECBO}$, and VPS decrease cost by $4.88 \%, 6.64 \%$, and $12.32 \%$, respectively. In this state, moment and shear on girder from optimal design of ECBO are $2.31 \%$ and $22.42 \%$ less than moment on girder form optimal design of CBO and VPS, respectively.

In 4-girder state, the VPS shows better performance than $\mathrm{CBO}$ and $\mathrm{ECBO}$. While in general state, VPS has better performance than $\mathrm{CBO}$ and $\mathrm{ECBO}$. In this state the reduction of the number of girders in VPS has a sound impact on decreasing the cost of the optimized design. In both states, the algorithms perform such that the optimized design does not need longitudinal stiffeners.

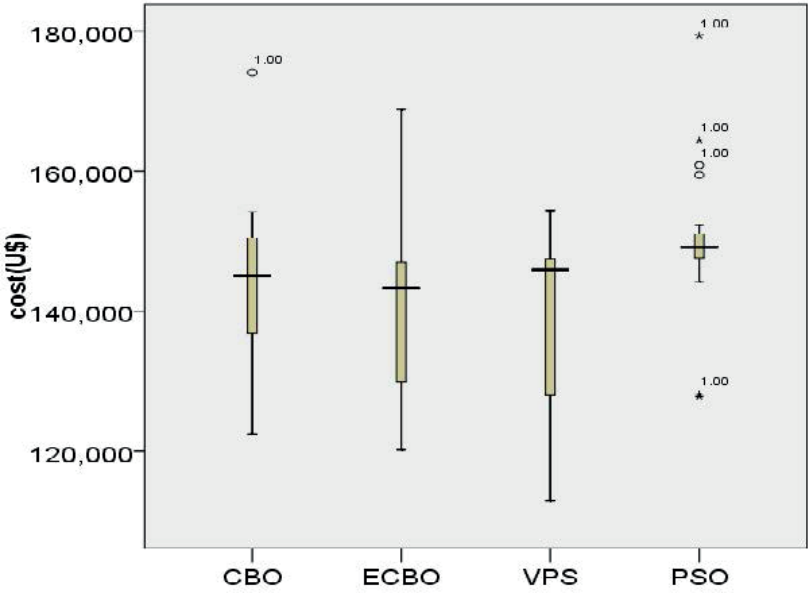

Fig. 20 Non-normal distributions of 36 runs of the general state

In 4-girder and general states, distribution of data from 36 runs, for VPS is higher than CBO and ECBO. For all three spans considered in this paper, VPS has better performance than ECBO and CBO. The best amount of Pro and population size are shown to be 0.3 and 30 , respectively. 

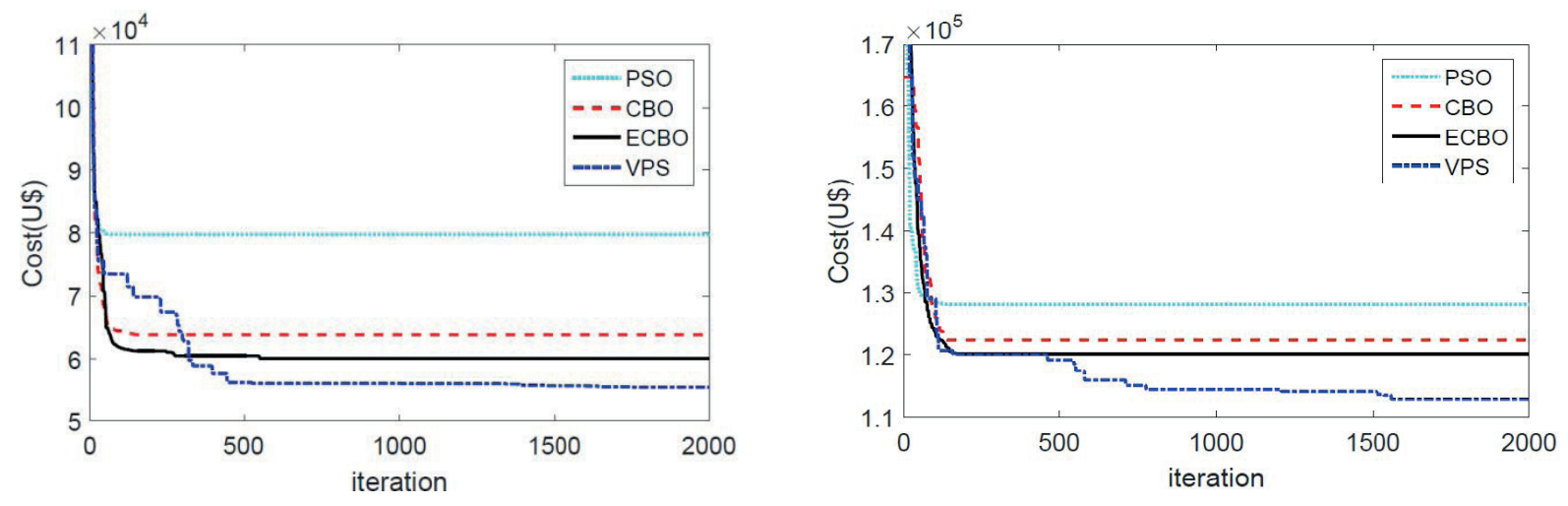

a) span $30 \mathrm{~m}$

b) span $40 \mathrm{~m}$

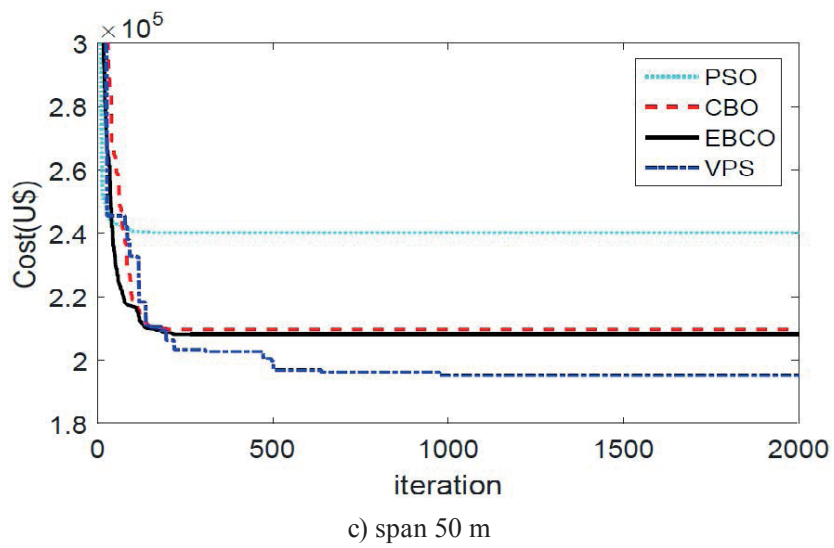

Fig. 21 Convergence curves of the algorithms with pop size $=30$

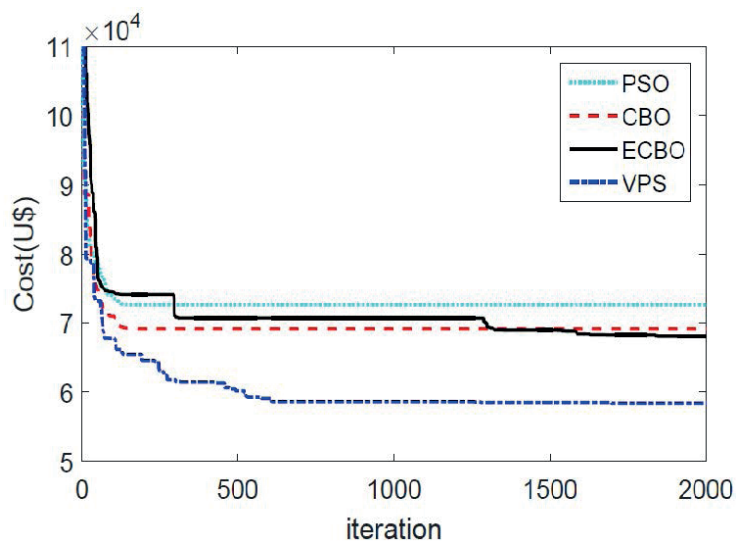

a) $\operatorname{span} 30 \mathrm{~m}$

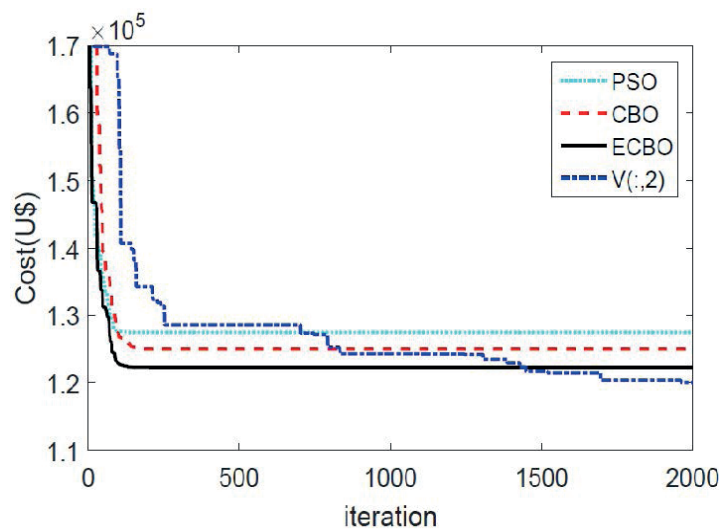

b) $\operatorname{span} 40 \mathrm{~m}$

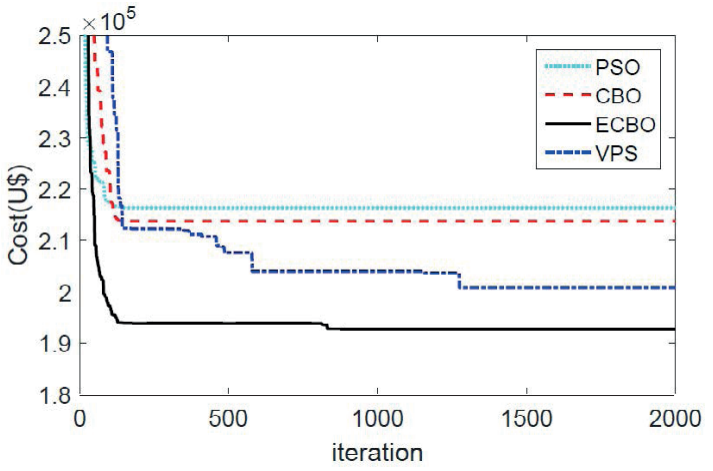

c) span $50 \mathrm{~m}$

Fig. 22 Convergence curves of the algorithms with pop size $=32$ 


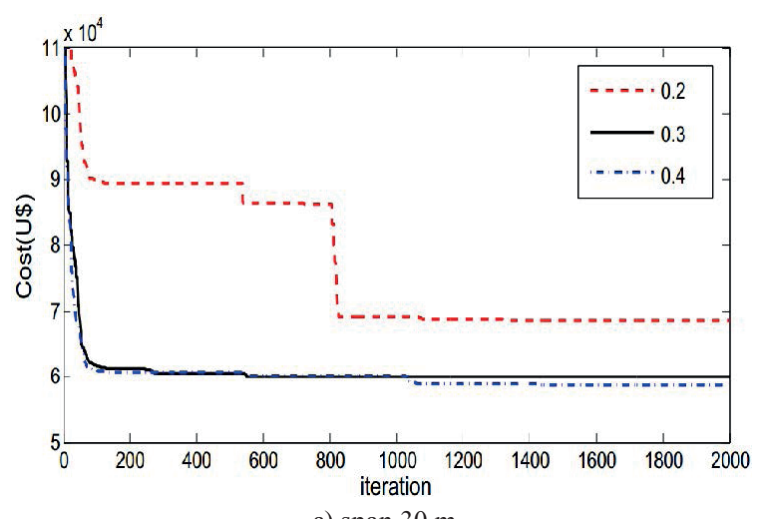

a) $\operatorname{span} 30 \mathrm{~m}$

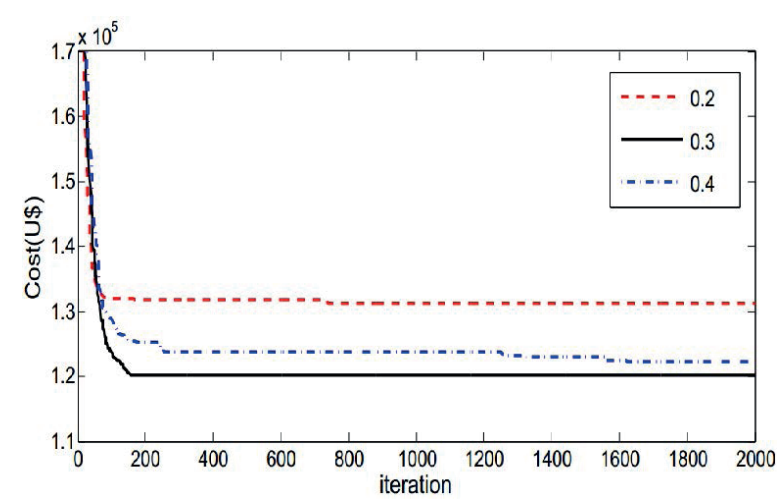

b) span $40 \mathrm{~m}$

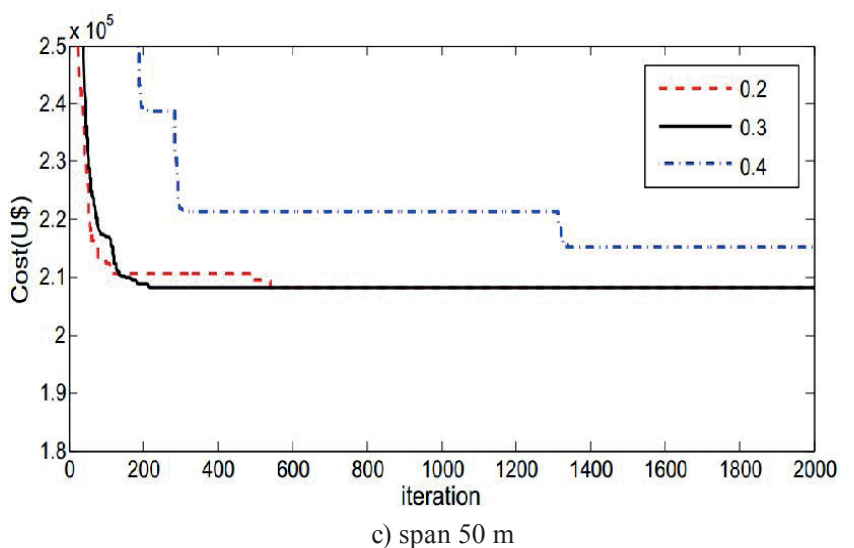

Fig. 23 Convergence curves of the ECBO for three different values of the coefficient values of Pro

\section{References}

[1] Kaveh, A., Mahdavi, V. R. "Colliding bodies optimization: A novel meta-heuristic method", Computers and Structures, 139, pp. $18-27,2014$.

https://doi.org/10.1016/j.compstruc.2014.04.005

[2] Kaveh, A., Ilchi Ghazaan, M. "Enhanced colliding bodies optimization for design problems with continuous and discrete variables", Advances in Engineering Software, 77, pp. 66-75, 2014. https://doi.org/10.1016/j.advengsoft.2014.08.003

[3] Kaveh, A., Ilchi Ghazaan, M. "A new meta-heuristic algorithm: Vibrating particles system", Scientia Iranica, 24(2), pp. 551-566, 2017.

http://doi.org/10.24200/SCI.2017.2417

[4] AASHTO, "Standard specifications for highway bridges", Association General Offices, Washington, D.C., USA, 2002.

[5] Nakamura, S., Momiyama, Y., Hosaka, T., Homma, K. "New technologies of steel/concrete composite bridges", Journal of Constructional Steel Research, 58(1), pp. 99-130, 2002. https://doi.org/10.1016/S0143-974X(01)00030-X

[6] Thevendran, V., Shanmugam, N. E., Chen. S., Liew, J. Y. R. "Experimental study on steel-concrete composite beams curved in plan", Engineering Structures, 22(8), pp. 877-889, 2000. https://doi.org/10.1016/S0141-0296(99)00046-2

[7] Chien, E. Y. L., Ritchie, J. K. "Composite floor systems - A mature design option", Journal of Constructional Steel Research, 25(1-2), pp. 107-139, 1993.

https://doi.org/10.1016/0143-974X(93)90055-W
[8] Yang, G.-T., Su. Q.-T. "Discussion on "Composite (steel-concrete) highway bridge fatigue assessment" by F.N. Leitão, J.G.S. da Silva, P.C.G. da S. Vellasco, S.A.L. de Andrade, and L.R.O. de Lima [J Constr Steel Res 2011; 67(1): 14-24]", Journal of Constructional Steel Research, 67(9), pp. 1411-1412, 2011. https://doi.org/10.1016/j.jcsr.2011.03.002

[9] Kim, Y. J., Tanovic, R., Wight, R. G. "A parametric study and rating of steel I-girder bridges subjected to military load classification trucks", Engineering Structures, 56, pp. 709-720, 2013. https://doi.org/10.1016/j.engstruct.2013.06.001

[10] Barth, K. E., Wu, H. "Development of improved natural frequency equations for continuous span steel I-girder bridges", Engineering Structures, 29(12), pp. 3432-3442, 2007. https://doi.org/10.1016/j.engstruct.2007.08.025

[11] Ghani Razaqpur, A., Shedid, M., Nofal, M. "Inelastic load distribution in multi-girder composite bridges", Engineering Structures, 44, pp. 234-247, 2012. https://doi.org/10.1016/j.engstruct.2012.05.014

[12] Jagtap, C. B., Shahezad, M. "Comparative study of prestressed concrete girder and steel plate girder for roadway over bridge", International Journal of Scientific Research in Science, Engineering and Technology, (2)1, pp. 113-117, 2016. http://ijsrset. com/IJSRSET162122

[13] Long, W., Troitsky, M. S., Zielinski, Z. A. "Optimum design of cable-stayed bridges", Structural Engineering and Mechanics, 7(3), pp. 241-255, 1999. 
[14] Kaveh, A., Massoudi, M. S. "Cost optimization of a composite floor system using ant colony system", International Journal of Optimization in Civil Engineering. 36(2), pp. 139-148, 2012. https://doi.org/10.22099/IJSTC.2012.631

[15] Kaveh, A. "Applications of metaheuristic optimization algorithms in civil engineering", 1st ed., Springer, Cham, Switzerland, 2017.

[16] Poitras, G., Lefrançois, G., Cormier, G. "Optimization of steel floor systems using particle swarm optimization", Journal of Constructional Steel Research, 67(8), pp. 1225-1231, 2011. https://doi.org/10.1016/j.jcsr.2011.02.016

[17] Hendawi, S., Frangopol, D. M. "Design of composite hybrid plate girder bridges based on reliability and optimization", Structural Safety, 15(1-2), pp. 149-165, 1994.

https://doi.org/10.1016/0167-4730(94)90057-4

[18] Luo, Y., Li, A., Kang, Z. "Reliability-based design optimization of adhesive bonded steel-concrete composite beams with probabilistic and non-probabilistic uncertainties", Engineering Structures, 33(7), pp. 2110-2119, 2011.

https://doi.org/10.1016/j.engstruct.2011.02.040

[19] Kaveh, A., Maniat, M., Naeini, M. A. "Cost optimum design of post-tensioned concrete bridges using a modified colliding bodies optimization algorithm", Advances in Engineering Software, 98, pp. 12-22, 2016. https://doi.org/10.1016/j.advengsoft.2016.03.003

[20] Pedro, R. L., Demarche, J., Miguel, L. F. F., Lopez, R. H. "An efficient approach for the optimization of simply supported steel-concrete composite I-girder bridges", Advances in Engineering Software, 112, pp. 31-45, 2017. https://doi.org/10.1016/j.advengsoft.2017.06.009

[21] Senouci, A. B., Al-Ansari, M. S. "Cost optimization of composite beams using genetic algorithms", Advances in Engineering Software, 40(11), pp. 1112-1118, 2009. https://doi.org/10.1016/j.advengsoft.2009.06.001

[22] Khatri, V., Singh, P. K., Maiti, P. R. "Comparative study of economical design aspect of steel-concrete composite bridge with MS, HPS and hybrid steel", International Journal of Engineering Research and Development, 4(6), pp. 62-68, 2012.

[23] Kravanja, S., Žula, T., Klanšek, U. "Multi-parametric MINLP optimization study of a composite I beam floor system", Engineering Structures, 130, pp. 316-335, 2017. https://doi.org/10.1016/j.engstruct.2016.09.012

[24] De Munck, M., De Sutter, S., Verbruggen, S., Tysmans, T. Coelho, R. F. "Multi-objective weight and cost optimization of hybrid composite-concrete beams", Composite Structures, 134, pp. 369377, 2015.

https://doi.org/10.1016/j.compstruct.2015.08.089

[25] García-Segura, T., Yepes, V. "Multiobjective optimization of post-tensioned concrete box-girder road bridges considering cost, $\mathrm{CO} 2$ emissions, and safety", Engineering Structures, 125, pp. 325-336, 2016.

https://doi.org/10.1016/j.engstruct.2016.07.012

[26] Hasan, Q. A., Badaruzzaman, W. H. W., Al-Zand, A. W. Mutalib, A. A. "The state of the art of steel and steel concrete composite straight plate girder bridges", Thin-Walled Structures, 119, pp. 988-1020, 2017.

https://doi.org/10.1016/j.tws.2015.01.014
[27] Linzell, D., Hall, D., White, D. "Historical perspective on horizontally curved i girder bridge design in the united states", Journal of Bridge Engineering, 9(3), pp. 218-229, 2004. https://doi.org/10.1061/(ASCE)1084-0702(2004)9:3(218)

[28] Su, D., Nassif, H., Xia, Y. "Optimization of deck construction staging for multiple-span continuous steel girder bridge", Journal of Performance of Constructed Facilities, 32(1), 2018. https://doi.org/10.1061/(ASCE)CF.1943-5509.0001073

[29] Glover, F. W., Kochenberger, G. A. "Handbook of Metaheuristics", 1st ed., Springer, Boston, MA, USA, 2003. https://doi.org/10.1007/b101874

[30] Dorigo, M., Maniezzo, V., Colorni, A. "The ant system: optimization by a colony of cooperating agents", IEEE Transaction on System, Man and Cybernetics B, 26(1), pp. 29-41, 1996. https://doi.org/10.1109/3477.484436

[31] Eberhart, R., Kennedy, J. "A new optimizer using particle swarm theory", In: Proceedings of the Sixth International Symposium on Micro Machine and Human Science, Nagoya, 1995, pp. 39-43. https://doi.org/10.1109/MHS.1995.494215

[32] Geem, Z. W., Kim, J. H., Loganathan, G. V. "A new heuristic optimization algorithm: harmony search", Simulation, 76(2), pp. 60-68, 2001. https://doi.org/10.1177/003754970107600201

[33] Holland, J. H. "Genetic algorithms", Scientific American, 267, pp. 66-72, 1992.

[34] Mirjalili, S., Mirjalili, S. M., Lewis, A. "Grey wolf optimizer", Advances in Engineering Software, 69, pp. 46-61, 2014. https://doi.org/10.1016/j.advengsoft.2013.12.007

[35] Kaveh, A., Talatahari, S. "A novel heuristic optimization method: charged system search", Acta Mechanica, 213(3-4), pp. 267-289, 2010. https://doi.org/10.1007/s00707-009-0270-4

[36] Kaveh, A., Motie Share, M. A., Moslehi, M. "A new meta-heuristic algorithm for optimization: magnetic charged system search", Acta Mechanica, 224(1), pp. 85-107, 2013. https://doi.org/10.1007/s00707-012-0745-6

[37] ABNT, "7188-carga móvel em ponte rodoviária e passarela de pedestre" Associação Brasileira de Normas Técnicas, Rio de Janeiro, Brazil, 1984. [in Portuguese]

[38] Kaveh, A., Ilch Ghazaan, M. "Meta-heuristic algorithms for optimal design of real-size structures", 1st ed., Springer, Chem, Switzerland, 2018.

[39] Xu, G., Yu, G. "Reprint of: On convergence analysis of particle swarm optimization algorithm", Journal of Computational and Applied Mathematics, 340, pp. 709-717, 2018. https://doi.org/10.1016/j.cam.2018.04.036

[40] Chen, K., Zhou, F., Wang, Y., Yin, L. "An ameliorated particle swarm optimizer for solving numerical optimization problems", Applied Soft Computing, 73, pp. 482-496, 2018. https://doi.org/10.1016/j.asoc.2018.09.007

[41] Lee, W.-S., Chen, Y.-T., Wu, T.-H. "Optimization for ice-storage air-conditioning system using particle swarm algorithm", Applied Energy, 86(9), pp. 1589-1595, 2009. https://doi.org/10.1016/j.apenergy.2008.12.025

[42] CAIXA, Sinapi: Sistema Nacional de Pesquisa de Custos e Índices da Construção Civil. Rio de Janeiro, Brazil, 2015. [in Portuguese] 